\title{
EL SIGNIFICADO AMBIVALENTE DEL RECONOCIMIENTO DEL DERECHO A LA ESPECIAL PROTECCIÓN EN COLOMBIA*
}

\section{THE AMBIVALENT MEANING OF THE RECOGNITION OF THE RIGHT TO SPECIAL PROTECTION IN COLOMBIA}

\author{
Holmedo Peláez-Grisales** \\ Fecha de recepción: 13 de febrero de 2016 \\ Fecha de aceptación: 20 de enero de 2017 \\ Disponible en linea: 30 de mayo de 2017
}

\section{Para citar este artículo/To cite this article}

Peláez-Grisales, Holmedo, El significado ambivalente del reconocimiento del derecho a la especial protección en Colombia, 134 Vniversitas, 249-290 (2017). http://dx.doi.org/10.11144/Javeriana.vj134.sard

doi:10.11144/Javeriana.vj134.sard

\footnotetext{
* Artículo de investigación resultado del proyecto doctoral Estudio de caso sobre el "derecho a la especial protección" de los habitantes de calle del rio Medellín, adelantado en el doctorado en derecho de la Facultad de Jurisprudencia, Universidad del Rosario, Bogotá, cofinanciado por la Facultad de Derecho de la Universidad Pontificia Bolivariana, Medellín, radicado en esta institución como Un nuevo derecho para los sujetos de especial protección en Colombia con el número 374B-03/15-37.

** Jurista colombiano. Doctorando en derecho, Facultad de Jurisprudencia, Universidad del Rosario, Bogotá, Colombia. Magíster en derecho privado. Profesor asociado del área de derecho público e investigador de la línea Derecho, Sociedad y Contexto del grupo de investigaciones en Derecho de la Escuela de Derecho y Ciencias Políticas de la Universidad Pontificia Bolivariana, Campus de Laureles, Circular 1 No. 70-01. Orcid.org/0000-0001-8619-2952; Researcher ID: D_1098-2017. Medellín, Colombia. Contacto: holmedo.pelaez@upb.edu.co; pelaez.holmedo@urosario.edu.co
} 


\section{RESUMEN}

Este artículo analiza de manera crítica el significado de la categoría jurídica del derecho a la especial protección en el ordenamiento jurídico colombiano y su relación con las teorías de reconocimiento. En un primer momento, sostiene que esta categoría tiene un significado positivo y negativo que obliga a entenderla como una herramienta política en permanente construcción y a interpretarla en sus distintas dimensiones y bifurcaciones. En un segundo momento, argumenta que este derecho tiene su fundamentación en las teorías de reconocimiento y, por tanto, se integra y articula a las tensiones y problemas de las formas de reconocimiento y; en un tercer momento, presenta las caras opuestas que, normalmente, envuelve este tipo de reconocimiento jurídico y; a partir de allí, alimenta la idea según la cual el derecho a la especial protección en Colombia promueve un modelo de reconocimiento formal y no material de los sujetos y grupos desaventajados y reproduce su desigualdad, mediante un nuevo discurso de los derechos, debajo del cual se esconde el viejo discurso del derecho moderno que termina por cuestionar el sentido positivo de esta categoría y afianzar su sentido negativo.

Palabras clave: Derecho a la especial protección; sujetos y grupos de especial protección; derecho excepcional; teorías de reconocimiento; formas de reconocimiento 


\section{ABSTRACT}

This article examines critically the meaning of the legal category of the right to special protection in the Colombian legal system and its relation with the theories of recognition. Firstly, the article argues that this category has a positive and negative meaning which needs to be understood as a political tool in permanent construction, and to be interpreted it in its various dimensions and subdivision. Secondly, the article argues that this right is based on the theories of recognition and, therefore, integrates and articulates to the tensions and problems of the forms of recognition. Thirdly, we present the opposite sides that are normally involved in this kind of legal recognition. From there, the article nurtures the idea, according to which, the right to special protection in Colombia promotes a model of formal and material recognition, not of disadvantaged subjects and groups, that represents their inequality by means of a new discourse of rights under which the old discourse of modern law hides, which, ultimately, ends up questioning the positive meaning of this category and reinforces its negative sense.

Keywords: right to special protection; subjects and groups of special protection; exceptional right; theories of recognition; forms of recognition

\section{SUMARIO}

INTRODUCCIÓN.- I. EL SENTIDO POSITIVO Y NEGATIVO DEL OBJETO JURÍDICO DEL DERECHO A LA ESPECIAL PROTECCIÓN.- II. EL RECONOCIMIENTO COMO FUENTE DEL OBJETO JURÍDICO DE LA ESPECIAL PROTECCIÓN DE LOS SUJETOS Y GRUPOS DESAVENTAJADOS.- III. LAS CARAS OPUESTAS DEL RECONOCIMIENTO EN LA ESPECIAL PROTECCIÓN.- CONCluSiONES.- Bibliografía. 


\section{INTRODUCCIÓN}

La categoría jurídica del derecho a la especial protección en Colombia promueve en el derecho colombiano una especie de teoría de "derechos especiales" "a favor" de ciertos sujetos y grupos que están discriminados, marginados o en circunstancias de debilidad manifiesta y, por tanto, en una situación de desventaja frente al resto de la población, conforme con el artículo 13 superior del texto constitucional ${ }^{1}$.

En este sentido, el derecho constitucional colombiano parece introducir una "fórmula jurídica especial" que busca remediar las injusticias y tratos indebidos que soportan aquellos individuos en el trayecto de su socialización, conforme con sus desventajas frente al sujeto "universal", "impersonal" y "abstracto" para el que se supone están dirigidas de forma general las leyes colombianas.

A partir de esa figura, se establece un derecho excepcional y particular para unos sujetos que se supone "especiales", a quienes el derecho colombiano les promete justicia, a partir de una igualdad real con solidaridad, como producto de un nuevo modelo constitucional y del Estado social y democrático de derecho.

En este entendido, la Corte Constitucional colombiana ha asumido la competencia de establecer progresivamente entre los años 1992 y 2016 ese derecho excepcional vía acción de tutela mediante su reiterada jurisprudencia, en la cual aparentemente desarrolla un significado positivo de la especial protección, con base en la siguiente premisa:

(...) el artículo 13 superior ordena al Estado promover las condiciones para que la igualdad sea real y efectiva y adoptar medidas a favor de grupos discriminados o marginados, asi como brindar protección especial a las personas que por su condición económica, física o mental, se encuentren en circunstancias de debilidad manifiesta ${ }^{2}$.

1 Colombia, Constitución Política de 1991, versión corregida 116 Gaceta Constitucional, 20 de julio de 1991. Disponible en: http://www.secretariasenado.gov.co/senado/basedoc/constitucion_politica 1991.html

2 En este sentido positivo, se puede destacar el estudio de la Corte Constitucional sobre la demanda de inconstitucionalidad parcial del artículo 2 de la Ley 1641 de 2013. En ella, los demandantes estimaron que la definición de habitante de calle, por medio de la cual fueron reconocidos legal y expresamente con medidas de especial protección, fue discriminatoria de los habitantes de la calle 
De este modo, ese sentido positivo de la categoría jurídica del derecho a la especial protección se ha introducido de manera acrítica en el discurso dominante del derecho colombiano y en la práctica social siendo, reiteradamente, usada en el contexto como la "fórmula jurídica apropiada" para rogar la tutela de unos "derechos especiales" condicionados al reconocimiento previo de un individuo dentro de una determinada identidad de un sujeto o grupo de especial protección.

En respuesta a ese discurso imperante, este artículo tiene como objetivo fundamental cuestionar ese sentido positivo de esta categoría del derecho colombiano y su modelo de reconocimiento; a partir de allí, se argumenta la tesis de que su significado es problemático por cuanto alberga un sentido negativo que se oculta debajo del ropaje de un discurso esperanzador y de promesas de justicia e igualdad, pero que en el fondo encubre una herramienta política discursiva que reproduce la exclusión y la subordinación de unos sujetos y grupos sociales frente a otros, mediante un modelo de reconocimiento politizado y con diferentes tensiones, caracterizado por ser unilateral, vertical, explícito, erróneo, restringido, incompleto, indirecto y sin fundamento teórico reconocible en una perspectiva unidimensional o bidimensional de la justicia, encerrado en el discurso del derecho moderno de la colonización en un período posmoderno y poscolonial actual.

El texto aborda la cuestión desde la sociología jurídica crítica en tres apartados:

\footnotetext{
que conservaban vínculos con sus familias, porque la norma solo consideró como habitantes de la calle solo a quienes tuvieran rotos sus vínculos con la familia. Al respecto, la Corte ubicó el problema en "analizar si la exigencia de haber roto vínculos con el entorno familiar, en tanto requisito para ser calificado como habitante de la calle generaba un desconocimiento del derecho a la igualdad". En su decisión concluyó que "la definición de la expresión 'habitante de la calle' condiciona el suministro de la protección constitucionalmente ordenada e incide de manera decisiva en el ámbito de los derechos fundamentales de sujetos de especial protección"; así las cosas, consideró que en el caso de los habitantes de calle "el énfasis está puesto en los factores socioeconómicos y que la condición de indigente o de habitante de la calle no se hace depender de la ruptura o del mantenimiento de los vínculos familiares"; en este orden de ideas declaró inexequible esta parte de la definición por "incurrir en inconstitucionalidad por violación del derecho a la igualdad de los habitantes de la calle que mantienen algún vínculo con su familia y propiciar su exclusión injustificada de los programas de protección dirigidos a este sector poblacional". Corte Constitucional, Sentencia C-385-14, 25 de junio de 2014, magistrado ponente Gabriel Eduardo Mendoza-Martelo. Disponible en: http://www. corteconstitucional.gov.co/relatoria/2014/c-385-14.htm. Colombia, Ley 1641 de 2013, por la cual se establecen los lineamientos para la formulación de la política pública social para habitantes de la calle y se dictan otras disposiciones, 48.849 Diario Oficial, 12 de julio de 2013. Disponible en: http://www.secretariasenado.gov.co/senado/basedoc/ley_1641_2013.html
} 
En un primer momento, comienza examinando "el sentido positivo y negativo del objeto jurídico de ese derecho a la especial protección", en el cual se problematiza el significado positivo incorporado incuestionadamente a esta categoría en el derecho colombiano y se revela su sentido negativo, al mostrar su significado opuesto sin llegar a enmarcarlo inmediatamente en un sentido $u$ otro.

En un segundo momento, para profundizar en el estudio de esta categoría se examina "el reconocimiento como fuente del objeto jurídico de la especial protección"; y por medio de este, se avanza en demostrar cómo la especial protección desde su fundamento es problemática, puesto que se integra y articula a las tensiones y problemas de las formas de reconocimiento, entre ellas, el derecho estatal.

Esta relación entre el reconocimiento y la categoría de la especial protección lleva a examinar las teorías de reconocimiento más influyentes que explican este proceso de socialización, entre las que se destacan las teorías de Axel Honneth, Nancy Fraser y Herbert Hart, quienes han planteado diferentes perspectivas y fundamentos del reconocimiento; esto es, en su orden: como medio de autorrealización personal, como una cuestión de justicia para la abolición de las estructuras de estatus y de clase que crean subjetividades despreciadas y como un asunto de la regla de reconocimiento del sistema jurídico.

Al mismo tiempo, el texto muestra cómo esos modos de reconocimiento son cuestionados desde las teorías de Judith Butler, Santiago Castro y Peter Fitzpatrick, por ser reproductores de un discurso poscolonial en la posmodernidad.

En medio de esa discusión, el derecho se presenta como una forma de reconocimiento, que en el caso colombiano, producto de una tradición jurídica occidental y del proceso de colonización, ha adoptado un modelo fundado en un prototipo foráneo, mediante el cual ha naturalizado la idea del reconocimiento pleno solo para un sujeto liberal, universal, abstracto y homogéneo, en desprecio de cualquier otra forma de reconocimiento que tenga en cuenta la pluralidad de las subjetividades existentes; lo cual ha sido garantizado gracias a concepciones positivistas dominantes que han servido para reproducir en el derecho interno ese discurso eurocentrista que, al mismo tiempo, mantiene viva la figura del subalterno, mediante 
la categoría jurídica de la especial protección, a partir de la cual se le garantiza un reconocimiento precario y de derecho excepcional que denota el sentido negativo de este tipo de reconocimiento.

Finalmente, en un tercer momento, el artículo plantea las caras opuestas del reconocimiento en la especial protección; esto es, identifica extremos disímiles que se pueden presentar y conformar diferentes tipos de reconocimiento en materia de especial protección $\mathrm{y}$, a partir de estas distinciones, el texto caracteriza el modelo de reconocimiento que opera en el derecho colombiano para los sujetos y grupos de especial protección, según el cual este se produce de forma unilateral, vertical, explícita, errónea, restringida, incompleta, indirecta y sin una perspectiva unidimensional ${ }^{3}$ o bidimensional $^{4}$ de la justicia y, en consecuencia, produce un efecto adverso al sentido positivo de la especial protección, esto es, reproduce la desprotección y la desigualdad material.

En estos términos, el texto finaliza afirmando la necesidad de desmitificar el sentido positivo de la categoría jurídica de la especial protección y verla en sus diferentes facetas, para sugerir la urgencia de problematizar estas categorías y combatir el sentido negativo de esta figura a partir de la reinvención del Estado y de un constitucionalismo experimental que cambie ese sentido negativo del modelo de reconocimiento de los sujetos y grupos desaventajados dentro del contexto colombiano.

3 Una perspectiva unidimensional defiende la tesis de que la justicia de igualdad de los especialmente protegidos se logra en el momento en que estos sujetos, luego de su lucha por el reconocimiento, son reconocidos e incluidos en la sociedad. En esta línea se interpreta la obra de AxEL HonNeTh, $L a$ lucha por el reconocimiento. Por una gramática moral de los conflictos sociales (Crítica, Grijalbo Mondadori, Barcelona, 1992).

4 Una perspectiva bidimensional defiende la tesis de que la justicia de igualdad de los sujetos especialmente protegidos requiere un proceso paralelo de reivindicación no solo del logro del reconocimiento de sus identidades, sino, también, de un proceso de redistribución de recursos necesaria para la superación de las injusticias de estatus y clase social. En este sentido se puede ver la obra de Nancy Fraser \& Axel Honneth, ¿Redistribución o reconocimiento?: un debate político-filosófico (Ediciones Morata, Madrid, 2003). 


\title{
I. EL SENTIDO POSITIVO Y NEGATIVO DEL OBJETO JURÍDICO DEL DERECHO A LA ESPECIAL PROTECCIÓN
}

\author{
El estudio del objeto jurídico del derecho a la especial protección \\ de ciertos sujetos y grupos de la sociedad ${ }^{5}$ plantea la necesidad \\ de cuestionar la pertinencia de esta categoría en el derecho como \\ instrumento jurídico utilizado, reiterativamente, en las últimas dos \\ décadas dentro del ordenamiento jurídico colombiano ${ }^{6}$, en especial,
}

5 Estos sujetos y grupos de especial protección pueden agruparse en cinco categorías: 1) En el grupo por sus circunstancias físicas: 1.1) en razón de la edad: los niños, niñas y adolescentes, juventudes, adulto mayor y tercera edad; 1.2) en virtud de alguna limitación física: las personas con una discapacidad física o capacidades diferentes. 2) En el grupo por sus condiciones psicológicas: las personas con alguna limitación mental o capacidades diferentes. 3) En el grupo de las víctimas de violencia generalizada: los desplazados, torturados, secuestrados, desaparecidos, refugiados, exiliados, líderes políticos y miembros de partidos políticos, periodistas y habitantes en zonas con problemas de orden público. 4) En el grupo de los sujetos tradicionalmente discriminados, por el sexo: las mujeres, madres cabeza de familia, mujeres en estado de embarazo; por la etnia o raza: indígenas, gitanos, negritudes, afrocolombianos, raizales, palenqueros; por el lenguaje: las minorías lingüísticas; por la orientación sexual: los LGTBIQ [lesbianas, gais, bisexuales, transexuales, intersexuales, queer]; por la nacionalidad: extranjeros, inmigrantes y migrantes colombianos; por el estado de salud: los que padecen una enfermedad grave, incurable o ruinosa y los incapacitados; por la orientación religiosa: las minorías religiosas; por la situación jurídica: las personas privadas de la libertad; por la calidad de trabajador: según el tipo de empleo. Y 5) en el grupo de los sujetos en condiciones de pobreza, inferioridad, subordinación, dependencia, marginalidad, territorio y precariedad económicas están los pobres, consumidores, trabajadores, desempleados, campesinos, mendigos, habitantes de calle y los damnificados. Holmedo Peláez-Grisales, Una mirada al problema del derecho de los sujetos y grupos desaventajados de especial protección en Colombia y la apuesta por una necesaria fundamentación teórica desde las teorías contemporáneas de la justicia, 17 Estudios Socio-Jurídicos, 1, 125-168 (2015). Disponible en: https://revistas.urosario. edu.co/index.php/sociojuridicos/article/view/3289/2631

6 La apropiación y el uso habitual de este objeto jurídico del derecho a la especial protección aparece en la nueva Constitución Política de Colombia de 1991 con la consagración nominativa y no taxativa de algunos sujetos y grupos de especial protección por parte del Estado. El artículo 13 superior señala expresamente: “...El Estado promoverá las condiciones para que la igualdad sea real y efectiva y adoptará medidas a favor de grupos discriminados o marginados". (...) "protegerá especialmente a aquellas personas que por su condición económica, física o mental, se encuentren en circunstancia de debilidad manifiesta". Además de ello, se suman otros fundamentos como: el preámbulo, los artículos 1 (fundamento del Estado social de derecho), 2 (fines esenciales del Estado), 13 (fundamento general de todos los sujetos de protección reforzada), 42 (hijos nacidos fuera del matrimonio), 43 (referido a las mujeres, al que está por nacer, a la mujer en embarazo y a la mujer cabeza de familia), 44 (protector de los niños), 45 (defensor de los adolescentes), 46 (referido a las personas de la tercera edad), 47 (protector de los disminuidos físicos, sensoriales y psíquicos), 49 (referido a la salud de las personas y a los enfermos), 50 (protege a todo niño menor de un año), 53 (referido al trabajador, a la mujer, a la maternidad y al trabajador menor de edad), 65 (defensor del productor de alimentos), 73 (protector especial del periodista), 85 (derechos de aplicación inmediata) y 86 (acción de tutela, instrumento de protección de los sujetos de especial protección). Colombia, Constitución Política de 1991, versión corregida 116 Gaceta Constitucional, 20 de julio de 1991. Disponible en: http://www.secretariasenado.gov.co/senado/basedoc/constitucion_politica_1991. html. Contrario a este régimen constitucional, la Constitución de 1886 fue más escueta al respecto, solo hacía referencia al caso de los extranjeros, cuyos derechos especiales la ley se encargaría de 
por parte del aparato judicial y administrativo y, tangencialmente, por el legislativo", para tratar de "remediar las injusticias sociales y abordar la cuestión de la igualdad material" entre los nacionales colombianos.

El derecho a la especial protección tiene un significado ambivalente, aún no tratado en el derecho. En el primer sentido, puede ser concebido como un dispositivo jurídico que permite revelar situaciones reales de injusticia; conceder medidas prestacionales, tradicionalmente adeudadas por el Estado y la sociedad y; ser un instrumento, por el cual se reconocen las diferencias y las desigualdades existentes entre los sujetos del derecho y la pertenencia a ciertos grupos desaventajados de la sociedad con el fin de implementar acciones afirmativas para la igualación de sus dere$\operatorname{chos}^{8}$ y avanzar en la solución justa de los conflictos sociales y en

regular; de los esclavos, que pisaran territorio colombiano, quienes quedaban libres. Colombia, Constitución Política de 1886, 5 de agosto de 1886. Disponible en: http://www.alcaldiabogota. gov.co/sisjur/normas/Norma1.jsp?i=7153. En lo demás, la Corte Suprema de Justicia reconoció la inconstitucionalidad de algunas normas que trataban injustamente a algunos sujetos de la sociedad; sin embargo, el problema no mereció la relevancia que ha mostrado bajo el nuevo régimen constitucional, ni tampoco los desarrollos constitucionales que se han presentado en estos tiempos.

7 Esta discriminación de la participación del órgano judicial y legislativo en el tratamiento de la especial protección dentro del derecho estatal se debe tener en cuenta, dado que la Corte Constitucional colombiana ha sido la que ha implementado este objeto jurídico a partir de su jurisprudencia constitucional; de ahí que en una de sus tempranas sentencias de tutela, Caso Jesús Herney Valdez, se puede ver esta iniciativa. Corte Constitucional, Sentencia T-347-96, 8 de agosto de 1996, magistrado ponente Julio César Ortiz-Gutiérrez. Disponible en: http://www.corteconstitucional.gov.co/ relatoria/1996/t-347-96.htm. Esta corporación cuenta hoy con más de mil novecientos (1900) pronunciamientos constitucionales, en sus sentencias de tutela, constitucionalidad y unificación. Por otro lado, en el caso del ejecutivo, este ha adoptado la especial protección mediante la implementación de una estructura administrativa en los distintos órdenes territoriales (nacional, departamental y municipal) conforme con Secretarías que, incluso, han sido denominadas de acuerdo con los sujetos y grupos de especial protección a fin de encargarlas de acciones afirmativas a su favor y, de otro lado, se han expedido algunas reglamentaciones al respecto. Finalmente, en el caso del legislador, se debe destacar que este no se refiere a estos sujetos y grupos con la denominación de especial protección, sino que ha tomado directamente a cada sujeto y ha legislado sobre cada uno, de forma particular, en por lo menos mil ochocientas leyes (1.800), así sobre niños, niñas y adolescentes (178 leyes), juventudes (91 leyes), adulto mayor (21 leyes), tercera edad (46 leyes), mujeres (141 leyes), madres cabeza de familia (29 leyes), mujeres en estado de embarazo (50 leyes), indígenas (12 leyes), gitanos (7 leyes), negritudes (15 leyes), afrocolombianos (7 leyes), campesinos (64 leyes), LGTBI (no se encuentra por este término, por diversidad hay 108 leyes), los discapacitados (11 leyes), disminuidos (42 leyes), inválidos (137 leyes), los que padecen de una enfermedad grave o ruinosa (67 leyes), los mendigos (14 leyes), indigentes (23 leyes), habitantes de calle (1 Ley), los damnificados (49 leyes), los desplazados (51 leyes), torturados, secuestrados o desaparecidos (116 leyes), refugiados (31 leyes), exiliados, líderes políticos, presos, extranjeros (413 leyes), inmigrantes (20 leyes). Recuperado de http://www.lexbase.com

8 En este sentido, como se ha destacado en citas anteriores, el ordenamiento constitucional colombiano intenta adherirse a este significado de la especial protección, en su "sentido positivo", lo cual puede ser contrastado con sus normas constitucionales, en especial el artículo 13 superior y la jurisprudencia de la Corte Constitucional. 
el desarrollo moral de la sociedad, como dice Axel Honneth en su teoría del reconocimiento?.

En este orden, la Corte Constitucional colombiana, máximo órgano de interpretación constitucional, desde esta perspectiva, ha desarrollado en su jurisprudencia, entre los años 1992 y 2015, el núcleo esencial y positivo de este postulado, como aquel que se traduce: i) en un tratamiento singularizado que se debe ajustar a las necesidades y requerimientos de los sujetos y grupos vulnerables ${ }^{10}$; ii) en suplir los déficits de protección que estos requieren para la garantía de su igualdad material ${ }^{11}$, por medio del aseguramiento de sus condiciones materiales para el ejercicio pleno de sus derechos y libertades ${ }^{12}$; en otras palabras, mediante el aseguramiento de un derecho a un mínimo de condiciones para su seguridad material, que consiste en garantizar el derecho a un mínimo vital o derecho a la subsistencia, que constituye el fundamento constitucional del futuro desarrollo legislativo del llamado "subsidio de desempleo"13; iii) en la facultad de neutralizar las situaciones violatorias de la dignidad humana, prestarles asistencia y protección y, sobre todo, en garantizarles la igualdad de oportunidades y su nivelación social en esta sociedad históricamente injusta y desigual, con factores culturales y económicos de grave incidencia en el "déficit social"14, iv) en el fundamento para adoptar acciones afirmativas, entendidas como políticas o medidas orientadas a reducir y eliminar las

9 Axel Honneth, La lucha por el reconocimiento. Por una gramática moral de los conflictos sociales, 8 (Crítica, Grijalbo Mondadori, Barcelona, 1992). Al respecto, para Honneth, el problema de los sujetos y grupos de especial protección es un problema de reconocimiento, fundado en una lucha moral por la inclusión de aquellos que han sido injustamente excluidos de las estructuras sociales. En la medida en que se dé una solución justa a este problema, se puede avanzar hacia el desarrollo moral de la sociedad.

10 Corte Constitucional, Sentencia T-275-15, 12 de mayo de 2015, magistrada ponente María Victoria Calle-Correa. Disponible en: http://www.corteconstitucional.gov.co/relatoria/2015/t-275-15.htm

11 Corte Constitucional, Sentencia T-092-15, 5 de marzo de 2015, magistrada ponente Gloria Stella Ortiz-Delgado. Disponible en: http://www.corteconstitucional.gov.co/relatoria/2015/t-092-15.htm

12 Corte Constitucional, Sentencia T-025-15, 23 de enero de 2015, magistrado ponente Gabriel Eduardo Mendoza-Martelo. Disponible en: http://www.corteconstitucional.gov.co/relatoria/2015/t-025-15. htm

13 Corte Constitucional, Sentencia C-1036-03, 5 de noviembre de 2003, magistrada ponente Clara Inés Vargas-Hernández. Disponible en: http://www.corteconstitucional.gov.co/relatoria/2003/c-1036-03. htm

14 Corte Constitucional, Sentencia T-426-92, 24 de junio de 1992, magistrado ponente Eduardo Cifuentes-Muñoz. Disponible en: http://www.corteconstitucional.gov.co/relatoria/1992/t-426-92.htm. Corte Constitucional, Sentencia C-1036-03, 5 de noviembre de 2003, magistrada ponente Clara Inés Vargas-Hernández. Disponible en: http://www.corteconstitucional.gov.co/relatoria/2003/c-1036-03. htm 
desigualdades sociales, culturales o económicas de aquellas personas o grupo ${ }^{15} \mathrm{y}$, como instrumentos diferenciales diseñados para asegurar la satisfacción de bienes y servicios en una sociedad caracterizada por la escasez ${ }^{16} ; \mathrm{v}$ ) en la construcción de las condiciones indispensables para asegurar a todos ellos una vida digna dentro de las posibilidades económicas que estén a su alcance; esto incluye la alimentación, la vivienda, la seguridad social y los escasos medios dinerarios para desenvolverse en sociedad ${ }^{17} \mathrm{y}$ vi) en el deber del Estado de aligerar las formalidades dentro del contexto de especial vulnerabilidad en el que se desenvuelven y hacer prevalecer el goce efectivo de sus derechos fundamentales, removiendo los obstáculos que les impiden acceder a las entidades del Estado; brindarles la asistencia requerida por medio de subsidios económicos ${ }^{18}$ y ampliar progresivamente la garantía de sus derechos económicos, sociales y culturales ${ }^{19}$.

En este sentido positivo, se inscriben, de otro lado, el tratadista Roberto Gargarella y algunos profesores de la Universidad de $Y_{\text {Yale }}^{20}$, quienes apuestan por defender esta categoría jurídica, que ellos denominan con el nombre de grupos desaventajados, a partir de la cual, por medio de su reconocimiento en un orden establecido, vislumbran la tesis de la necesidad de reformar el derecho "(...) para poder hacer frente a una realidad antes inexistente o ignorada: una realidad que nos dice que dentro de nuestra sociedad existen grupos (esto es, las mujeres; las minorías étnicas; los menores de edad), que no reciben el 'debido trato que merecen'; en consecuencia, esta categoría en sentido positivo permite introducir los cambios

15 Corte Constitucional, Sentencia C-371-00, 29 de marzo de 2000, magistrado ponente Carlos GaviriaDíaz. Disponible en: http://www.corteconstitucional.gov.co/RELATORIA/2000/C-371-00.htm

16 Corte Constitucional, Sentencia T-500-02, 27 de junio de 2002, magistrado ponente Eduardo Montealegre-Lynett. Disponible en: http://www.corteconstitucional.gov.co/relatoria/2002/t-500-02. htm

17 Corte Constitucional, Sentencia C-1036-03, 5 de noviembre de 2003, magistrada ponente Clara Inés Vargas-Hernández. Disponible en: http://www.corteconstitucional.gov.co/relatoria/2003/c-1036-03. htm

18 Corte Constitucional, Sentencia T-275-15, 12 de mayo de 2015, magistrada ponente María Victoria Calle-Correa. Disponible en: http://www.corteconstitucional.gov.co/relatoria/2015/t-275-15.htm

19 Corte Constitucional, Sentencia C-767-14, 16 de octubre de 2014, magistrado ponente Jorge Ignacio Pretelt-Chaljub. Disponible en: http://www.corteconstitucional.gov.co/relatoria/2014/c-767-14.htm. Corte Constitucional, Sentencia T-032-15, 26 de enero de 2015, magistrado ponente Jorge Ignacio Pretelt-Chaljub. Disponible en: http://www.corteconstitucional.gov.co/relatoria/2015/t-032-15.htm

20 Entre ellos, Akhil Reed Amar, Drew Days, Owen Fiss, Peter Schuck, Reva B. Siegel, Robert A. Burt y Vichy Schultz. 
jurídicos necesarios para asegurar un 'trato justo', también, a los sectores (hoy) más desaventajados dentro de la sociedad" 21.

Este grupo de estudiosos es consciente de las innumerables objeciones teóricas y prácticas a esta perspectiva, entre las que se destacan aquellas que señalan que las políticas preferenciales violentan (...) el principio según el cual nadie debe ser tratado peor a partir de circunstancias que no están bajo su propio control; el principio de la distribución de los costos y beneficios sociales conforme con los méritos de cada uno y; además, resulta difícil justificar por qué se pretende dar una ayuda especial a ciertos grupos (desfavorecidos) y no a otros 22 .

A partir de allí, el sentido positivo de la especial protección empieza a difuminarse, de un lado, mediante argumentos e intereses individualistas que, en últimas, dejan claro que esta perspectiva no es ajena a los cuestionamientos, en especial de los sectores que, tradicionalmente, han ocupado una mejor posición en la sociedad o como dice Roberto Gargarella, que han gozado de un "debido trato" y se oponen al cambio social por temor a perder o ver menguada esa posición privilegiada.

Pero, de otro lado, este sentido positivo parece perderse, también a la vista de algunos de los sujetos y grupos que defiende, quienes no parecen estar de acuerdo con esta denominación de especial protección, por distintas razones, entre las que se enuncian, por ejemplo, el peligro de ser re-estigmatizados con esta categoría, el hecho de universalizar o generalizar los intereses de los sujetos en unos grupos determinados, al discriminar a unos en favor de otros $\mathrm{y}$, en consecuencia, impedir la identificación de unos sujetos con las identidades establecidas dentro del grupo y, por tanto, llevar al fraccionamiento de estos grupos y de sus luchas sociales, lo que produce lo que Roberto Gargarella llama la "balcanización” de la

21 Roberto Gargarella, Los déficits del sistema político representativo, en Derecho y grupos desaventajados, 13-15 (Roberto Gargarella, comp., Gedisa, Barcelona, 1999).

22 Roberto Gargarella, Argumentos y contraargumentos en la discusión sobre los derechos de los grupos desaventajados, en Derecho y grupos desaventajados, 23-30, 23-24 (RoBERTo GARGARELLA, comp., Gedisa, Barcelona, 1999). 
sociedad en una multitud de [sujetos y] grupos enfrentados entre $\mathrm{sí}^{23}$ en una lucha por su reconocimiento ${ }^{24}$.

En este orden, se halla el segundo sentido de la especial protección, es decir, en su concepción negativa, a través de la cual, este objeto jurídico resulta mejor entendido como una herramienta jurídica discursiva ${ }^{25}$ que esconde dos premisas ${ }^{26}$ :

En un primer lugar, contribuye con el reconocimiento negativo y la clasificación de los sujetos y grupos sociales por estatus y clases, entre sujetos normales y sujetos especiales o, lo que es lo mismo, entre sujetos con derechos plenos y sujetos con derechos incompletos, sin que se produzcan cambios favorables y significativos que tiendan a ampliar ${ }^{27}$ de manera justa los derechos de los denominados sujetos y grupos de especial protección, volviéndolos más vulnerables al menosprecio social al designarles tal categoría que los identifica como sujetos incapaces de ser titulares de derechos plenos.

23 Roberto Gargarella, Argumentos y contraargumentos en la discusión sobre los derechos de los grupos desaventajados, en Derecho y grupos desaventajados, 23-30, 25 (RoBerto GARGARELla, comp., Gedisa, Barcelona, 1999).

24 Axel Honneth, La lucha por el reconocimiento. Por una gramática moral de los conflictos sociales (Crítica, Grijalbo Mondadori, Barcelona, 1992). Allí, Honneth plantea el conflicto social como la lucha por el reconocimiento, una lucha moral que no debe llevar a esa "balcanización" pues es una lucha por la vida buena en la que se busca un reconocimiento recíproco, que implica reconocer al otro en su totalidad, en su individualidad y su diferencia. En este sentido, Axel plantea, precisamente, que estamos ante esa lucha en la que se desconoce a ciertos sujetos y grupos sociales, y que, en últimas, lo que se debe evitar es un modelo de reconocimiento que atente contra la totalidad del individuo, puesto que esto impediría avanzar hacia el desarrollo moral de la sociedad. Nancy Fraser (2003), en cambio, va más allá de esta perspectiva unidimensional del conflicto social de la desigualdad; advierte que esa lucha entre los individuos es bidimensional, esto es, implica un reconocimiento de la diferencia en el que la integración de la mayoría o las normas culturales dominantes no sean el precio de un respeto igual y, también, una redistribución justa de los recursos y de la riqueza. En ambas posturas, se alude al peligro de una categoría que englobe un tratamiento generalizado para los sujetos y grupos de especial protección, en armonía con la crítica dentro del texto. NANCY FRASER \& AXEl Honneth, ¿Redistribución o reconocimiento?: un debate político-filosófico (Ediciones Morata, Madrid, 2003).

25 William Twining, Derecho y globalización, 83 (Siglo del Hombre Editores, Bogotá, 2003). Al respecto, Twining advierte que la regla de derecho está limitada por los cambios sociales en respuesta a las presiones políticas reales, pero al tiempo da la impresión de ser estable y fiel a los precedentes. Es decir, conforme esta premisa, una regla de derecho como la contenida en el derecho a la especial protección puede ser bien establecida como una regla formal, que pretende dar la idea de generar cambios a favor de los más desaventajados de la sociedad pero que en la práctica nada cambia su realidad.

26 Así se concluye del proyecto de investigación doctoral etnográfica Estudio de caso sobre el "Derecho a la Especial Protección” de los Habitantes de Calle del Río Medellín, de Holmedo PeláezGrisales, aprobado en acta del 29 de enero de 2016 por el doctorado en derecho de la Facultad de Jurisprudencia, Universidad del Rosario (Bogotá).

27 Cuando se habla de ampliar los derechos, se refiere a ensanchar aquellos que están restringidos o negados injustamente en relación con aquellos sujetos de la sociedad que reciben un "trato debido" y no a la pretensión de tener más y mejores derechos que otros. 
Y, en un segundo lugar, sirve como un instrumento jurídico que promete unos mejores derechos, unos derechos especiales de mayor protección inalcanzables, envueltos en ese reconocimiento formal de su identidad como sujetos y grupos de especial protección, cuya noción está viciada de un fundamento ontológico de la teología medieval que vende la idea del reino prometido en los cielos; según la cual Hans Lindahl, referenciando a Carl Schmitt ${ }^{28}$, cuestiona irónicamente que en ese proceso de reconocimiento ciertos sujetos ven sometida la materialización de sus derechos a la condición suspensiva de su disfrute en el reino de los cielos y no en la tierra ${ }^{29}$.

En suma, la denominación de especial protección sobre determinados sujetos y grupos no puede ser aceptada de forma definitiva bajo la idea de una concepción estructurada, apolítica, coherente, benéfica y justa. Pero tampoco puede ser concebida bajo el extremo de su acepción negativa, como un medio discursivo utilizado para la exclusión, la dominación y la subordinación permanente de unos sujetos respecto de otros. En particular, en contexto de desconocimiento generalizado de derechos.

Con ello se quiere decir que el significado de la regla de derecho ${ }^{30}$ de la especial protección sobre los sujetos y grupos desaventajados es una regla imperfecta y contradictoria, carece de los límites de toda regla de derecho que inciden en el contenido de esta acepción, como

28 Hans Lindahl, Constituent Power and Reflexive Identity: Towards an Ontology of Collective Selfhood, en The Paradox of Constitutionalism, 9-24 (Martin Loughlin \& Neil Walker, eds., Oxford University Press, Oxford, 2007). Al respecto, Lindahl le da la razón a Carl Schmitt, cuando afirma que la relación moderna entre constituyente y poder constituido es impensable sin la teología medieval, por ello se traslada esta idea a la concepción de los sujetos y grupos de especial protección. En este pasaje, Hans Lindahl referencia a Schmitt, para sustentar la idea de la autoconstitución de un sistema de gobierno, mediante el cual se sustenta la ontología de la identidad colectiva, que en la democracia seculariza la trascendencia de Dios, es decir, en la identidad del gobernante y los gobernados, las personas, en su relación con el ordenamiento jurídico, se hacen cargo de la posición de Dios y, es en esa relación que, bajo una concepción de la especial protección, parece volverse discursiva o al menos ideal.

29 Hans Lindahl, Constituent Power and Reflexive Identity: Towards an Ontology of Collective Selfhood, en The Paradox of Constitutionalism, 9-24 (Martin Loughlin \& Neil Walker, eds., Oxford University Press, Oxford, 2007).

30 Balakrishnan Rajagopal, Invoking the Rule of Law in Post-conflict Rebuilding: A Critical Examination, 49 William \& Mary Law Review, 4, 1347-1376 (2008). Disponible en: http://scholarship.law.wm.edu/cgi/viewcontent.cgi?article $=1145 \&$ context $=$ wmlr. Rajagopal dice que, entendida como una regla invocada del rule of law, es una regla que adolece de los mismos vicios y críticas que se le plantean a esta regla. El estado de derecho es un régimen insuficiente de normas formales; sus reglas son incompletas, inconsistentes y ambiguas y a esto no escapa la regla del derecho a la especial protección. 
lo sostiene William Twining ${ }^{31}$, esto es, se enfrenta a una dicotomía entre teoría y práctica, cuyo mayor límite está en el problema de la abstracción ${ }^{32}$.

Este problema hace que la regla de ese derecho tenga un núcleo blando o flexible que impide hallar un significado unívoco positivo o negativo sobre la categoría. Así pues, resulta difícil decir con certeza qué es ser un sujeto y grupo de especial protección, quiénes entran en esta categoría, cuál es la justificación para ello, quién tiene la autoridad para hacer tal designación, qué prerrogativas o consecuencias se derivan de allí, y qué coherencia hay entre el significado teórico y el práctico.

En esta línea, Balakrishnan Rajagopal ha puesto en tela de juicio la pretendida ilusión de una regla de derecho como una herramienta técnica, legal y apolítica o con un sentido plenamente determinado; en su lugar, advierte que esta regla esconde muchas contradicciones entre las diferentes agendas políticas ${ }^{33}$. Esto se entiende como una objeción a la idea de un significado claro respecto de la regla de derecho de los sujetos y grupos de especial protección ${ }^{34}$.

31 William Twining, Derecho y globalización, 27 (Siglo del Hombre Editores, Bogotá, 2003).

32 William Twining, Derecho y globalización, 28-29 (Siglo del Hombre Editores, Bogotá, 2003). Como también dice Twining, la categoría jurídica del derecho a la especial protección no es ajena a los límites de la regla de derecho, esto es, su significado está dado por las circunstancias sociales, culturales y políticas de un contexto determinado, por las prácticas predominantes de una teoría jurídica y posiciones hegemónicas, así como por las prácticas de resistencia y por los contextos de producción y recepción de discursos teóricos transnacionales. En este sentido, Axel Honneth tiene razón cuando señala que el reconocimiento recíproco de ese otro considerado de especial protección depende del desarrollo moral de cada sociedad determinada. El significado positivo o negativo de esta figura se entiende mejor como un concepto en pugna dentro de lo local pero permeado por un momento de globalización del derecho que lo complejiza.

33 Balakrishnan Rajagopal, Invoking the Rule of Law in Post-conflict Rebuilding: A Critical Examination, 49 William \& Mary Law Review, 4, 1347-1376 (2008). Disponible en: http://scholarship.law. wm.edu/cgi/viewcontent.cgi?article $=1145 \&$ context $=$ wmlr. Aquí, Rajagopal señala con razón que la regla de derecho está limitada por el contexto histórico y político, en el cual los distintos discursos jurídicos han tenido diferentes orígenes, significados, relaciones, intereses y transformaciones. En este sentido, el significado del objeto jurídico de la especial protección en Colombia debe ser concebido a partir del contenido complejo de distintos discursos y cambios en los que el ordenamiento jurídico estatal formal, es solo uno de muchos órdenes jurídicos coexistentes.

34 Brian Z. TAmanaha, The Dark of the Relationship between the Rule of Law and Liberalism, 3 NYU Journal of Law \& Liberty, 516-547 (2008). Disponible en: http://www.law.nyu.edu/sites/default/ files/ECM_PRO_060975.pdf. Así mismo, en este estudio, Tamanaha muestra que el significado de la regla de derecho está siempre permeado por los aspectos políticos y económicos del modelo liberal que se imponen, haciendo que las normas económicas se superpongan a otros valores para controlar el mundo, lo que hace que la concepción de la llamada especial protección no deje de estar determinada por este límite y que no pueda concebirse de manera ingenua, en su sentido meramente positivo. 
Ahora bien, para mostrar, aún más, este sentido ambivalente del significado de esta institución jurídica, Roberto Gargarella destaca, con razón, argumentos que defienden el sentido positivo de la figura, entre los que aparecen, primero, que la mayoría de las Constituciones modernas no parecen negar la posibilidad de establecer políticas especiales a favor de grupos desaventajados; segundo, que el objetivo que se pretende defender no es constitucionalmente impermisible, además parece ser un objetivo valioso y urgente desde el punto de vista constitucional: contribuir a que ningún sujeto y grupo resulte arbitrariamente desaventajado o conserve su situación tradicional de desventaja, porque lo cierto es que hay infinidad de grupos hipotéticamente necesitados de un "apoyo social especial" que requieren una atención prioritaria ${ }^{35}$.

Esta categoría debe ser analizada en toda su complejidad como una herramienta política en permanente construcción, que debe ser interpretada en sus distintas dimensiones, facetas y bifurcaciones, muchas veces, de forma contradictoria, para descifrar el significado de la especial protección en cada caso y medir sus implicaciones positivas y negativas. Esto es, su contenido y alcance deben mirarse en cada contexto desde lo local, sin obviar la incidencia global y las variaciones y las pugnas políticas que hay detrás de ella.

De esta manera, la incertidumbre y las contradicciones en el significado y la admisibilidad de este objeto jurídico de la especial protección dentro de un ordenamiento establecido están siempre presentes en su concepción analítica, en el uso que los actores del derecho le dan y en la aceptación o recepción que la sociedad y los sujetos "especiales" hacen de este ${ }^{36}$.

35 Roberto Gargarella, Argumentos y contraargumentos en la discusión sobre los derechos de los grupos desaventajados, en Derecho y grupos desaventajados, 23-30, 25-26 (RoBerto GARGARELla, comp., Gedisa, Barcelona, 1999).

36 William Twining, Derecho y globalización, 105-106 (Siglo del Hombre Editores, Bogotá, 2003). Esta aproximación al objeto bajo estudio obliga a comprender, como lo sostiene Twining, que la conceptualización de la regla de derecho, en este caso sobre un derecho especial para los sujetos y grupos de especial protección, está limitada por los cambios sociales en respuesta a las presiones políticas reales y debe sobrepasar los límites impuestos por el monismo jurídico, basados en que hay solo una fuente formalmente legítima de derecho, que es el Estado-nación [lo que desconoce otras fuentes no estatales que también producen derecho]; por el contrario, se deben ampliar esos límites hacia la perspectiva del pluralismo jurídico y superar el discurso individualista metodológico, según el cual las reglas son representaciones, ideas, conceptos que representan — como un mapael terreno y los obstáculos que nos confrontan en el mundo externo, ya que esto deja por fuera las actuaciones dialógicas [que no siempre son coherentes y que construyen distintos discursos]. Así pues, en el significado de la regla de la especial protección, hay también reglas incluso, formal- 
Lo anterior lleva a afirmar que el problema de la significación de la especial protección está ineludiblemente atado a una cuestión de política de los derechos y a la relación divergente entre una pluralidad de órdenes normativos ${ }^{37}$, en medio de los cuales la concepción de esta categoría puede ser entendida — de hecho-en sentidos diferentes.

\section{EL RECONOCIMIENTO COMO FUENTE DEL OBJETO JURÍDICO DE LA ESPECIAL PROTECCIÓN DE LOS SUJETOS Y GRUPOS DESAVENTAJADOS}

La cuestión del significado de los sujetos y grupos de especial protección plantea la urgente necesidad de revisar la fuente de producción de estas subjetividades, para ahondar en su sentido crítico, pues, a partir de allí, se pueden hallar buenas razones para explicar el núcleo de configuración y desarrollo de esta institución.

Esto es, el significado que se deriva de la especial protección para ciertas tipologías sociales tiene su fuente en un proceso de conocimiento, por medio del cual se determinan cuáles grupos o individuos son objeto de reconocimiento en el trayecto cultural de formación de una sociedad dada ${ }^{38}$. Es decir, se ve fundado en un acto social, mediante el cual se constituyen los sujetos por las distintas fuentes normativas, formales e informales, que no es más que un acto de reconocimiento, por medio del cual se reconocen y/o establecen ciertas identidades fijas que se conciben como "naturales" dentro de una comunidad concreta en desprecio de otras subjetividades.

Este acto de reconocimiento - que desde el inicio es problemático, en la medida en que implica una inclusión y exclusión de sub-

mente, no establecidas y en las que intervienen relaciones múltiples y complejas que no pueden ser desconocidas a la hora de conceptualizarla, entre ellas, aquellas que vienen del discurso de los sujetos y grupos de especial protección.

37 Esto hace referencia a la relación entre el orden dominante del derecho estatal y los demás órdenes no estatales, como los que se producen en las prácticas sociales de los sujetos y grupos de especial protección.

38 Con esto se advierte que las identidades de los sujetos y grupos de especial protección que son objeto de encuadramiento en esta categoría, tienen un origen cultural y no natural; esto es, sus identidades son construidas a partir del acto de reconocimiento del otro. Así lo han destacado Georg Wilhelm Friedrich Hegel, Axel Honneth, Nancy Fraser y Judith Butler. 
jetividades - opera como un presupuesto y fundamento necesario y en movimiento para explicar la configuración de esta categoría de sujetos y grupos especiales y, en ese sentido, resulta fundamental para mostrar la matriz del reconocimiento ${ }^{39}$ de la cual se deriva el significado de la especial protección.

Así, el estudio del reconocimiento permite mostrar que ese proceso en el que resultan reconocidas unas subjetividades generales, otras especiales y otras no reconocidas o invisibilizadas en esas dos perspectivas universalizantes de los sujetos, comprende un acto intersubjetivo de identificación cultural, política y psicológica de los individuos entre sí y de estos con las normas establecidas por la familia, la sociedad, el Estado y los demás órdenes normativos que operan en un contexto social determinado; a partir del cual se establecen y ensanchan los derechos y se motivan las luchas sociales por la inclusión de aquellas subjetividades excluidas y por la ampliación de sus derechos. El reconocimiento, pues, entraña diferentes tensiones de intereses políticos entre los individuos de una sociedad concreta ${ }^{40}$.

Lo anterior ha sido problematizado en los desarrollos teóricos del tema, por medio de los cuales se sustentan diferentes concepciones, fundamentos y formas del reconocimiento, y se pueden ver distintas tensiones teóricas asociadas a los modelos de reconocimiento $\mathrm{y}$, en particular, a los reconocimientos de los sujetos y grupos de especial protección.

Al respecto, entre los máximos exponentes del reconocimiento aparece Axel Honneth, a quien le asiste razón cuando sustenta que ese acto de reconocimiento ha sido concebido desde la filosofía social moderna por Thomas Hobbes y Nicolás Maquiavelo, como aquel, por el cual, la vida social está determinada con base en una relación de lucha por la autoconservación, en la que se cree que el

39 Judith Butler, El género en disputa. El feminismo y la subversión de la identidad (Ediciones Paidós, Barcelona, 1990). Al respecto, es importante tener en cuenta la tesis de Butler sobre la construcción de las subjetividades, para señalar que el acto de reconocimiento entre los individuos está limitado por matrices culturales naturalizadas por la sociedad, que excluyen otras identidades que los individuos desarrollan en la práctica social. Por tanto, esta idea de reconocer a los individuos bajo la condición de las subjetividades culturales dominantes reconocidas, entraña una norma social excluyente de otras subjetividades.

40 En este caso, la cuestión de este modelo de reconocimiento opera teniendo como presupuesto un Estado con una organización política basada en un sistema democrático y en un principio de estado de derecho en sentido moderno - occidental-. 
acrecentamiento de poder del individuo garantiza su reconocimiento. Por otro lado, desde la filosofía práctico-política, a partir de la teoría de reconocimiento de Hegel, quien cuestionó esa postura, discutiendo esa visión individualista y sustentando una noción intersubjetiva, según la cual el acto de reconocimiento, es un acto de lucha del individuo por la aceptación de su identidad como garantía de su libertad y, en ese sentido, el reconocimiento es fundado en motivos morales y no en la autoconservación, por cuanto, además, persigue la formación de una comunidad integrada por ciudadanos libres. Posteriormente, Hegel reorienta el acto de reconocimiento hacia una filosofía de la conciencia, según la cual el reconocimiento es un proceso de constitución del espíritu, donde el sujeto "se reconoce a sí mismo en otra totalidad semejante"; esto es, el individuo solo puede estar seguro de que es reconocido por el otro por la experiencia de la reacción práctica, es decir, el desarrollo de la identidad personal de un sujeto está ligado al presupuesto de determinados actos de reconocimiento de otros ${ }^{41}$.

A partir de estas posiciones, Axel Honneth retoma la teoría de Hegel y la actualiza con la teoría psicológico social de George H. Mead, recogiendo también la idea de que el sujeto crea su identidad por la experiencia de un reconocimiento intersubjetivo, que se explica en la medida en que, primero, un sujeto adquiere la conciencia de sí mismo a partir de una segunda persona; segundo, el sujeto interioriza e interactúa las normas sociales que resultan de la generalización de las expectativas de comportamiento de todos los miembros de la sociedad y, tercero, el sujeto pasa por un proceso de autoafirmación como una forma de defensa del propio yo frente al entorno social, que se da en el desplazamiento de la voluntad común hacia una comunidad de derecho ampliada, lo cual se convierte en la fuente de nuevos reconocimientos o en la motivación de las luchas sociales por el reconocimiento ${ }^{42}$.

Lo anterior deja ver que el acto de reconocimiento transporta la experiencia que vivencian los individuos, en el proceso intersubjetivo de construcción de su identidad, a partir de la cual estos pueden

41 Axel Honneth, La lucha por el reconocimiento. Por una gramática moral de los conflictos sociales (Crítica, Grijalbo Mondadori, Barcelona, 1992).

42 Axel Honneth, La lucha por el reconocimiento. Por una gramática moral de los conflictos sociales (Crítica, Grijalbo Mondadori, Barcelona, 1992). 
ver incluida o excluida su subjetividad o su "etiqueta" dependiendo de una cierta "voluntad común"43 , presumida en los órdenes normativos de un contexto social, que opera como una regla imperativa universalizante, producto del conflicto social. En este sentido, el individuo en este proceso pasa por al menos dos niveles de definición de su identidad, es decir, primero, es envuelto en la idea de un sujeto general como miembro de una comunidad determinada y forma su identidad a partir de su pertenencia a un grupo social y; segundo, el sujeto, en defensa de su individualidad, emprende un conflicto por su inclusión conforme con sus particularidades y abre paso a un segundo nivel de identidades que forman la categoría de los sujetos diferentes o particulares, quienes también a partir de sus características son agregados y/o asociados con ciertas identidades de grupo, como ocurre en el caso de los sujetos de especial protección.

Allí, Honneth parece plantear el reconocimiento, como aquel en el cual el sujeto se enfrenta a una lucha permanente de identidad en un contexto dividido en un centro, donde se presume existen unos sujetos capaces de albergar una identidad general, producto de unas normas sociales asimiladas y de una voluntad común y, la periferia, donde tienen lugar las individualidades, que, por medio de sus luchas, promueven la ampliación de ese centro.

Visto así, el reconocimiento se postula como un acto de inclusión y exclusión al mismo tiempo; es incluyente, cuando la identidad de un sujeto encaja en la matriz de las expectativas de la voluntad común de los miembros de la sociedad y, es excluyente, cuando esa subjetividad no se ajusta a esa matriz general, es diferente o

43 Axel Honneth, La lucha por el reconocimiento. Por una gramática moral de los conflictos sociales, 105 (Crítica, Grijalbo Mondadori, Barcelona, 1992). En esta obra de Honneth, esa voluntad común o colectiva es reconstruida desde Mead y Hegel como aquella surgida del proceso de ensanchamiento paulatino de contenidos de reconocimiento jurídico, a partir de un otro generalizado que se forma de las expectativas de comportamiento esperado de los demás miembros de una sociedad; conforme con el cual se forma el yo individual y se lanzan nuevas pretensiones de derecho para el reconocimiento de otros individuos y la ampliación de esa comunidad. De otro lado, según Lindahl (2007), esa voluntad común alude a un yo colectivo, que se forma a partir de una autoconstitución colectiva de una unidad política por medio de un ordenamiento jurídico. Aquí, este concibe ese yo colectivo en forma de cuestionabilidad, con posibilidades de innovación y de ruptura como poder constituyente en nombre de la comunidad política. Así también, en otros términos, la voluntad común puede ser vista como la voluntad dominante de un conjunto de individuos que han administrado el poder y han disciplinado al individuo y una sociedad determinada. Hans Lindahl, Constituent Power and Reflexive Identity: Towards an Ontology of Collective Selfhood, en The Paradox of Constitutionalism, 9-24 (Martin Loughuin \& Neil Walker, eds., Oxford University Press, Oxford, 2007). 
particular y, por tanto, es despreciada, desconocida o invisibilizada, al ser extraña a lo fijado como común.

El sujeto se enfrenta, pues, a este proceso experimental, a partir de tres formas de reconocimiento: el amor, el derecho y la valoración social, como bien destaca Axel Honneth, al menos, en tres órdenes normativos o de reconocimiento, en un primer orden, la familia; en un segundo orden, la sociedad; y, en un tercer orden, el Estado ${ }^{44}$; los cuales, sin desconocer que hay otros órdenes normativos ${ }^{45}$, sirven como ejemplos, para mostrar que en ellos, el individuo afronta el proceso de socialización, en cuya relación intersubjetiva, su identidad se ve adecuada o enfrentada a una lucha por el reconocimiento.

Nancy Fraser confronta este modelo casi indivisible de un individualismo excluyente de lo relacional y de agencias colectivas, y propone entender el reconocimiento como una cuestión de justicia y no de realización personal, pues considera que el reconocimiento se funda en la injusticia que se manifiesta en algunos individuos y grupos, a quienes se les niega el estatus de interlocutores plenos en la interacción social como consecuencia de unos patrones institucionalizados de valor cultural en cuya elaboración no han participado en pie de igualdad y, sin embargo, resultan menospreciados en sus características distintivas. Así, considerar el reconocimiento como un tema de justicia es tratarlo como un asunto de estatus social y una cuestión de agencia política cuando se advierte a los sujetos de especial protección mismos.

En esta perspectiva, propone entender el reconocimiento con un enfoque bidimensional, mediante el cual cada práctica social es tratada como económica y cultural al mismo tiempo, tanto desde el punto de vista de la distribución como desde el del reconocimiento, sin reducir ninguna de estas perspectivas a la otra.

En suma, Fraser sostiene que el reconocimiento debe tener en cuenta tanto la estructura de clases que hay en las sociedades modernas, que institucionalizan unos mecanismos económicos que niegan de forma sistemática a algunos de sus miembros los medios

44 Estas tres formas de reconocimiento pueden ser estudiadas en Axel Honneth, La lucha por el reconocimiento. Por una gramática moral de los conflictos sociales (Crítica, Grijalbo Mondadori, Barcelona, 1992).

45 Por ejemplo, otros órdenes normativos establecidos por comunidades particulares, como indígenas, gitanos, comunidades religiosas, habitantes de la calle o por organizaciones internacionales, entre otras. 
y las oportunidades que necesitan para participar en la vida social en pie de igualdad y, también, debe concebir la jerarquía de estatus, que institucionaliza unos patrones culturales que niegan por completo a algunos miembros el reconocimiento que necesitan para participar plenamente ${ }^{46}$.

Ahora bien, de estas dos corrientes principales del reconocimiento se destacan lo problemático del momento y los lugares desde los cuales se le está concibiendo; esto es, Axel Honneth ubica el reconocimiento en un momento original en el cual el individuo entra en relación de conocimiento con el mundo, en medio del cual advierte una intersubjetividad que funda siempre una fuente de conflicto entre los individuos por el reconocimiento recíproco de su individualidad que, cuando es desconocida, se convierte en la motivación para la lucha por el reconocimiento. En cambio, Nancy Fraser va más allá de centrar el proceso del reconocimiento en el conflicto del individuo y su lucha por su individualidad, y se ubica en el lugar de las subjetividades despreciadas y su lucha con las prácticas sociales históricas y las estructuras de clase y estatus que están naturalizadas en una sociedad y que son la fuente tradicional de la injusticia y de la lucha por el reconocimiento. Es decir, Honneth funda el reconocimiento en la experiencia individual de cada sujeto sin anexarle identidades despreciadas fijadas, mientras Fraser, necesariamente, defiende el reconocimiento en un contexto de opresión de los sujetos identificados bajo ciertas tipologías despreciadas.

A partir de allí, más allá de las distancias de estas perspectivas, el reconocimiento es el acto social en movimiento que opera entre los actores de una sociedad determinada, desde las instituciones hacia los individuos, desde estos hacia las instituciones y entre ellos mismos, como el instrumento de identificación de los sujetos y sus subjetividades, de su inclusión o exclusión dentro de un contexto social, así como medio para fijar estructuras de clase y estatus, pero también como fuente de lucha para la eliminación de esas estructuras de injusticias fijadas y el ensanchamiento de las subjetividades; esto significa la posibilidad de nuevos reconocimientos y de nuevas realidades.

46 Nancy Fraser \& Axel Honneth, ¿Redistribución o reconocimiento?: un debate político-filosófico (Ediciones Morata, Madrid, 2003). 
Por tanto, el reconocimiento, en el objeto jurídico de la especial protección, se manifiesta como la forma antecedente que ha asimilado unas subjetividades particulares en ese proceso de identificación de los sujetos y grupos de una comunidad y, como la fuente de motivación de la lucha por la ampliación del reconocimiento de estos y otros sujetos particulares no reconocidos y la abolición de las estructuras de estatus y de clase que los oprimen injustamente.

Lo anterior puede ser más revelador, cuando se pasa de ese reconocimiento como acto general y se entra en el derecho, como una forma de reconocimiento destacada por Honneth, pues es fundamental concebir el derecho como un espacio de lucha política y de reconocimiento multidimensional, en el cual, dependiendo de cada sociedad y de su estado de su lucha social, los sujetos son incluidos o excluidos dentro de los sistemas normativos y, en razón de ello, impulsan sus conflictos sociales. En este sentido, es adecuado acoger la perspectiva de Nancy Fraser, cuando advierte que en el reconocimiento siempre hay un contexto de opresión.

En ese orden, resulta importante tener en cuenta la tesis de Judith Butler cuando se refiere a que el acto de reconocimiento de los sujetos es un acto cultural y no un hecho natural, que está determinado por matrices culturales naturalizadas por la sociedad y el derecho, a partir de las cuales, los sujetos y grupos adquieren significados fijos mediante un procedimiento regulado de repetición que establece unos prototipos obligatorios frente a cada sujeto o grupo, para prescribir su identidad desde afuera, de forma dominante, y desconocer la pluralidad de las identidades ${ }^{47}$. De esta forma, el derecho ha hecho su labor de fijar y reproducir unos arquetipos de sujetos, en medio de disputas y en contravía de las realidades existentes en la sociedad.

Así, también, Peter Fitzpatrick, sobre este punto específico, refiriéndose al reconocimiento del sujeto moderno y la subjetividad jurídica, muestra cómo estos están creados, a partir de una matriz cultural, bajo un mito del derecho moderno, producto de una administración disciplinaria. La administración liberal moderna, que

47 Judith Butler, El género en disputa. El feminismo y la subversión de la identidad(Ediciones Paidós, Barcelona, 1990). 
encarna una unión particular del poder y el conocimiento, que crea una subjetividad particular ${ }^{48}$.

En consecuencia, el derecho como forma de reconocimiento sigue la lógica de ese acto general de reconocimiento, opera como una norma que establece unas subjetividades generales y abstractas, que son consideradas como normales dentro de una sociedad, en oposición a las subjetividades particulares, que son vistas como lo anormal, desconociendo, pues, las zonas grises de la subjetividad y convirtiendo estas últimas en sujetos de opresión y exclusión.

En estos términos, los sujetos abstractos, disciplinados por el derecho de la modernidad, como lo destaca Peter Fitzpatrick, han sido creados bajo la idea de un sujeto en términos de individualidad, homogéneo, autorresponsable, necesariamente reflexivo y con la autonomía necesaria, que rompe los vínculos limitadores de una comunidad natural. Este nuevo sujeto es el centro de un universo social y está siempre en una diferencia constante y esencial del "nativo" y otros diversos equivalentes del estado salvaje; esto es, el sujeto de la modernidad es concebido como un sujeto "universalizante" y "natural" que solo se reconoce en un sujeto liberal semejante y desconoce otra realidad ${ }^{49}$.

En ese contexto de clave colonial de la modernidad, surge el reconocimiento de los llamados sujetos y grupos especiales en Colombia, como opuestos al sujeto de la modernidad, como sujetos y colectivos particulares, diferenciados, débiles, discriminados, inferiorizados, faltos de una especial protección; que por medio de un derecho excepcional se establece una forma de reconocimiento para los sujetos y grupos subordinados al sujeto moderno.

En este sentido, Santiago Castro también afirma que esa construcción y la identificación del sujeto en los sistemas jurídicos provienen de ese fenómeno de la colonialidad ${ }^{50}$, entendida no solo como un fenómeno económico y político sino también epistémico de la modernidad, es decir, como un fenómeno producto de las ciencias sociales modernas, que creó el imaginario sobre el mundo social del "subalterno" (el oriental, el negro, el indio, el campesino) que no

48 Peter Fitzpatrick, La mitología del derecho moderno, 125-150 (Siglo XXI, México, 1998).

49 Peter Fitzpatrick, La mitología del derecho moderno, 125-150 (Siglo XXI, México, 1998).

50 Santiago Castro-Gómez, La poscolonialidad explicada a los niños, 19-20 (Editorial Universidad del Cauca, Instituto Pensar, Pontificia Universidad Javeriana, Bogotá, 2005). 
solo sirvió para legitimar el poder imperial en el nivel económico y político, sino que creó paradigmas acerca de las identidades de colonizadores y colonizados en el derecho ${ }^{51}$.

Peter Fitzpatrick, por su parte, agrega que ese proyecto de la modernidad trajo consigo la idea de lo trascendente a la tierra, donde el "hombre" ya sería la medida del hombre, pero con ello también creó los monstruos contra los cuales luchaba: los monstruos de la raza y la naturaleza que marcan los límites exteriores, el "otro" intratable contra el cual la Ilustración opone lo universal; así el ser ilustrado sería lo que el otro no $\mathrm{es}^{52} \mathrm{y}$, ante esa disyuntiva de la subjetividad, es creado el derecho moderno ${ }^{53}$.

Así, el sujeto del derecho moderno se crea a partir de la figura del reconocimiento de un sujeto universal naturalizado que es el sujeto europeo, quien se diferencia del resto de los hombres y, construye su propia identidad, a partir de la creación de una identidad fija de su opuesto, esto es, del americano, el oriental, el asiático y el africano que reconoce bajo la idea de sujetos con una naturaleza silvestre indómita; discurso dominante que sirvió a sus propósitos para sustentar su misión colonizadora en los distintos continentes ${ }^{54}$. Ahora, esas dinámicas del racismo en el reconocimiento del otro no se han quedado atrás; se han reproducido y se reproducen hoy por medio de nuevas formas de colonialismo interno; la deli-

51 Esta construcción de los sujetos se aparta de la tesis de Michael Hardt y Antonio Negri, quienes en su libro Imperio, sostienen que las jerarquías moderno/coloniales han desaparecido y que ello abre una oportunidad para una pluralidad de mundos posibles. Sin embargo, aquí se acoge la tesis de Castro, quien con razón sustenta esa división. SANTIAGo CASTRo-Gómez, La poscolonialidad explicada a los niños, 65-71 (Editorial Universidad del Cauca, Instituto Pensar, Pontificia Universidad Javeriana, Bogotá, 2005).

52 Peter FitzPatrick, La mitología del derecho moderno, 46-47 (Siglo XXI, México, 1998).

53 Aquí, nuevamente es importante tener en cuenta la idea de la teología medieval inmersa en el derecho y que sustenta el reconocimiento y la figura de la especial protección, como se mencionó antes con Carl Schmitt y Hans Lindahl. Esta tesis se refuerza con lo dicho por Peter Fitzpatrick, cuando sostiene que el derecho moderno tomó la posición de Dios, es decir, ya el soberano no es el representante terrenal de Dios, ahora el derecho tiene un origen autónomo y autosuficiente. En este sentido, Fitzpatrick agrega que siendo el orden la primera ley de los cielos, cuando la Ciudad de Dios es traída a la tierra, el orden se convierte en la primera ley de la naturaleza; así se sustituye a Dios con la naturaleza, lo cual está de acuerdo con el derecho natural, el cual cree que es tal entre todas aquellas naciones que están más avanzadas en la civilización. Peter FitzPatrick, La mitología del derecho moderno, 49-53 (Siglo XXI, México, 1998). A partir de este presupuesto, se intenta naturalizar la construcción de las subjetividades, se construye un sujeto ilustrado, a partir del mito de la naturaleza que se divide entre los sujetos con naturaleza apropiada y sujetos con naturaleza silvestre siendo en el primer caso el sujeto que se ajusta al orden universal de las cosas el que para ser un sujeto soberano encuentra su identidad en diferencia con la naturaleza silvestre.

54 Además de Peter Fitzpatrick y Santiago Castro, puede leerse a Immanuel Wallerstein, Walter Mignolo y Enrique Dussel. 
mitación y el reconocimiento de unos sujetos y grupos de especial protección en Colombia para reconocerles derechos, a diferencia del sujeto general y abstracto del derecho, surgen como un modelo de reconocimiento que sirve a los propósitos del sujeto liberal de la modernidad para reconocer su opuesto y mantener las estructuras de estatus y de clase heredadas de ese colonialismo europeo.

Este es el origen del reconocimiento del otro dentro del derecho, a quien se le fija una identidad diferente, cuyo nacimiento se deriva de la creación del racismo europeo, a partir del cual el mundo fue reducido a términos europeos ${ }^{55}$; es decir, todo lo que quedara por fuera de este se concebía como algo distinto a lo que debía $\operatorname{ser}^{56}$.

En consecuencia, el derecho moderno ${ }^{57}$ se convirtió en la forma de reconocimiento, mediante el cual se identificaba al sujeto universal occidental, en contrapartida de cualquier otro sujeto, y sirvió como vehículo de ese discurso dominante e instrumento ideológico, que se ha extendido a las demás formas de reconocimiento entre los individuos y que ha permeado los demás órdenes normativos como la familia, la sociedad y otras comunidades particulares.

Así pues, estas últimas perspectivas acerca del reconocimiento de los sujetos permiten contemplar la fuente histórica en que se

55 Peter FitzPatrick, La mitología del derecho moderno, 66-68 (Siglo XXI, México, 1998).

56 Santiago Castro-Gómez, La poscolonialidad explicada a los niños, 55-64 (Editorial Universidad del Cauca, Instituto Pensar, Pontificia Universidad Javeriana, Bogotá, 2005). En este sentido, se acoge la perspectiva de Enrique Dussel, la cual se interpreta bajo la idea de que el reconocimiento del otro que es diferente, ha sido útil para construir las identidades propias del sujeto occidental y, viceversa, las identidades universalizantes del oriental, asiático, africano y americano han determinado el sujeto universalizante europeo. Esta cuestión se acerca en las formas a la teoría expuesta por Axel Honneth, pero se aleja en cuanto a las expectativas morales de los conflictos sociales.

57 Pier Giuseppe Monateri \& Geoffrey Samuel, La invención del derecho privado, 98-110 (Siglo del Hombre Editores, Bogotá, 2006). Sobre ese origen del derecho como forma de reconocimiento en la tradición jurídica occidental, aquí se entiende cuestionado por Pier G. Monateri, quien sostiene que esa titularidad sobre el origen es una invención de los europeos como una estrategia ideológica para defender su superioridad cultural sobre otros pueblos, a fin de excluir a los no europeos de la fundación de esa tradición e imponer la construcción de un proyecto que asume la función de delinear el marco de diferencias entre un nosotros y un ellos, un centro y una periferia, un oeste y un este $\mathrm{y}$, en definitiva, un tipo de sujeto ideal universalizante en desprecio de las demás subjetividades. Monateri, acertadamente, demuestra que este origen del derecho no es producto únicamente de la cultura occidental romana, sino que este tiene un origen multicultural que desconoce la contribución de las subjetividades extrañas al europeo. Por tanto, siendo dominante la versión europea, la construcción del derecho como forma de reconocimiento ha sido construida bajo un arquetipo de exclusión en el cual las subjetividades no europeas no son tenidas en cuenta. Paradójicamente, esta ha sido la fuente tradicional indiscutible del derecho colombiano que se ha transmitido en los textos jurídicos del ordenamiento jurídico colombiano y en la enseñanza de las facultades de derecho del país. Esto ha conducido al orden jurídico colombiano a la adopción de esa forma de reconocimiento desde la exclusión de las subjetividades que se aparten de ese modelo heredado. 
han producido y cómo estas estructuras de reconocimiento entre los sujetos se han mantenido y se reproducen aún en la posmodernidad. Al respecto, Santiago Castro, citando a Walter Mignolo, afirma que hay nuevas condiciones creadas por el capitalismo global para asistir a una reorganización posmoderna de la colonialidad de las subjetividades y advierte que el colonialismo como fenómeno constitutivo de la modernidad no se ha terminado y se extiende aún en la posmodernidad ${ }^{58}$.

Así, el caso colombiano es un ejemplo claro de cómo el derecho como forma de reconocimiento, espacio en el que un tipo de acto se configura o como arena de definición de los términos del reconocimiento mismo, de forma vertical, se ha construido a partir de un contexto de lucha desde la colonización, surgida en la modernidad, que trasciende hasta nuestros días, fundado en un reconocimiento de exclusión de ciertas subjetividades, mediante la formación del otro opuesto y subalterno que aquí se identifica bajo la categoría de los sujetos y grupos de especial protección.

El derecho colombiano - como producto de la tradición jurídica occidental - funda su modelo de reconocimiento a partir de prototipos foráneos y establece la idea de reconocimiento solo para un sujeto liberal, universal, abstracto y homogéneo, en desprecio de cualquier otra tipología de subjetividades.

En ese discurso de exclusión, las concepciones positivistas del derecho, creadas desde afuera, han servido para reproducir en el derecho colombiano ese discurso eurocentrista dominante, homogéneo y subalterno; primero, por medio del derecho monista impuesto en la colonización española en América y, luego, por medio de teorías del derecho hegemónicas que replican ese discurso, entre ellas, la teoría pura del derecho de Hans Kelsen, la cual, a partir de una recepción particular, ha sido dominante en la tradición jurídica colombiana y ha servido a esos propósitos de edificar un derecho estatal que intenta naturalizar el orden de las cosas, incluyendo los sujetos del derecho, desconociendo otras realidades por fuera de él ${ }^{59}$.

58 Santiago Castro-Gómez, La poscolonialidad explicada a los niños, 71-77 (Editorial Universidad del Cauca, Instituto Pensar, Pontificia Universidad Javeriana, Bogotá, 2005).

59 Hans Kelsen, La teoría pura del derecho (Editorial Trotta, Madrid, 1934). Aquí, Kelsen aparece como el máximo exponente del positivismo jurídico del siglo XX. Así también lo ha reconocido el tratadista Diego López-Medina (2008), quien ha afirmado que este produjo un giro lingüístico en la cultura jurídica contemporánea, mediante la focalización en el derecho como lenguaje, la cual 
Así también, la tesis de Herbert Hart sobre el reconocimiento, en su concepción del derecho como referente foráneo e influyente en contextos contemporáneos como el colombiano, revela esa regla de exclusión de las subjetividades cuando lo define a partir de la combinación de las reglas primarias, que prescriben que los seres humanos hagan $u$ omitan ciertas acciones, y las reglas secundarias, que establecen que los seres humanos pueden, haciendo o diciendo ciertas cosas, introducir nuevas reglas primarias, extinguirlas, modificarlas y controlarlas ${ }^{60}$.

Allí, en la noción del derecho de Hart, la idea de la exclusión se presenta cuando intenta defender su concepción del derecho por medio de un sistema armónico de reglas, al trasladar el poder de definición de qué es el derecho a las reglas primarias y secundarias, y universalizar dentro de ellas la concepción de los sujetos; esto se presenta en la medida en que las subjetividades que son reconocidas solo son aquellas que resultan establecidas en el sistema jurídico estatal de forma vertical a partir de las reglas secundarias, y no por las reglas primarias de obligación, ya que según aquel, estas últimas por sí solas no lo constituyen ${ }^{61}$.

llevó a una actitud "antihermenéutica" que se basaba, no en convicciones políticas (...) sino en tesis epistemológicas y lingüísticas. A partir de allí, el lenguaje y la hermenéutica jurídicas han creado una gramática, una semántica y una pragmática lingüísticas excepcionales y de especialidad de sus profesionales, que se aleja del sentido común de la comunidad lingüística. Diego López-Medina, $L a$ letra y el espiritu de la ley: reflexiones pragmáticas sobre el lenguaje del derecho y sus métodos de interpretación, 5-13 (Editorial Temis, Bogotá, 2008). Por tanto, al contrario de esta postura, López defiende la tesis de que el derecho es, en términos generales, lenguaje ordinario y que los usuarios profesionales del mismo deberían usarlo dentro de este marco en su interacción con la ciudadanía en general. Esta última perspectiva permite entender el derecho en un sentido más amplio e incluyente dentro de la realidad que opera y, como forma de reconocimiento, permitiría mayores reconocimientos de los sujetos que actúan en esa comunidad lingüística. Diego López-Medina, La letra y el espiritu de la ley: reflexiones pragmáticas sobre el lenguaje del derecho y sus métodos de interpretación, 15 (Editorial Temis, Bogotá, 2008).

60 Herbert Hart, El concepto del derecho, 101-102 (Abeledo Perrot, Buenos Aires, 1941).

61 Herbert Hart, El concepto del derecho, 101-108 (Abeledo Perrot, Buenos Aires, 1941). Al respecto, Hart plantea este problema en el aspecto interno y externo de las reglas; el interno se da cuando un grupo acepta y usa las reglas como pauta de conducta y el externo, cuando adopta la posición de mero observador y no las acepta. Concluye sobre este asunto que cualquier sociedad regida por reglas, jurídicas o no, consiste en la tensión de quienes aceptan voluntariamente las reglas y quienes las rechazan. Ahora bien, para resolver este problema, Hart sostiene la tesis a partir de la noción de la obligación en las reglas primarias y secundarias, según la cual, donde hay normas jurídicas, la conducta humana se hace en algún sentido no optativa u obligatoria. En estos términos, el derecho como la máxima pauta de conducta determina los sujetos de manera obligatoria y advierte que quienes adoptan el punto de vista externo están sometidos a la exclusión que viene de la seriedad de esa presión social que se encuentra en las reglas que dan origen a obligaciones y se someten a las diversas formas de presión que se adoptan en la sociedad, incluso a las sanciones físicas. 
Lo anterior se ve con mayor claridad cuando Hart introduce la idea de la "regla de reconocimiento" 62 en el derecho como una regla para la identificación incontrovertible de las reglas primarias de obligación y, a partir de allí, el reconocimiento es visto como una forma propia para hallar estas reglas con cualidades "naturales" que permiten decir con autoridad de Dios cómo identificar el derecho, como si el derecho no pudiera escapar a su justificación teológica. En ese sentido, todo lo extraño a esas "fuentes indiscutibles" de reconocimiento, que resultan naturalizadas, no es concebido como derecho ${ }^{63}$.

En este sentido, también, la incorporación de la teoría de reconocimiento de Hart como lente único de comprensión del derecho tiende a reproducir las características de la concepción del derecho occidental, como un sistema positivado con pretensiones de certeza que contribuye a sostener la idea de un reconocimiento fijo y universal, que desconoce la pluralidad de ordenamientos normativos que operan en una sociedad determinada y, por tanto, niega la existencia de otras formas de reconocimiento, lo cual resulta favorable al proyecto de la colonialidad y poscolonialidad de las subjetividades.

En consecuencia con todo lo anterior, el reconocimiento de las subjetividades particulares dentro del derecho colombiano, cuando no son desconocidas de forma total, son reconocidas de forma imperfecta, es decir, son reconocidas no desde la reciprocidad a la que se refiere Axel Honneth ${ }^{64}$, sino desde la diferencia desigual, que

62 Herbert Hart, El concepto del derecho, 110 (Abeledo Perrot, Buenos Aires, 1941). Según Hart, la regla de reconocimiento es un remedio a la falta de certeza de las normas primarias de obligación, que permite reconocer de forma indiscutible las reglas de un grupo, a partir de una forma propia para hallar estas reglas: sea la escritura, lista o inscripción revestida de autoridad. Esta regla marca un signo de unidad y autoridad que da la idea de un sistema jurídico. Por tanto, la idea del reconocimiento de los sujetos está determinada no conforme con la identidad individual y plural de los sujetos, sino de forma universalizante por la comunidad bajo la idea de un sujeto genérico único y por una autoridad superior al mismo sujeto.

63 Herbert Hart, El concepto del derecho, 116-120 (Abeledo Perrot, Buenos Aires, 1941).

64 Axel Honneth, La lucha por el reconocimiento. Por una gramática moral de los conflictos sociales (Crítica, Grijalbo Mondadori, Barcelona, 1992). En este punto, se debe entender que la teoría del reconocimiento recíproco propuesta por Axel Honneth promueve un reconocimiento de la vida buena del individuo, en donde el sujeto puede crear su identidad desde la diferencia pero en términos de igualdad, como el resto de individuos de la sociedad a la que pertenece, siempre que las pretensiones sobre su identidad sean fundadas en buenas razones, lo que abre la posibilidad para las nuevas luchas sociales. Así, para Honneth, el punto de partida del reconocimiento es la noción de que los sujetos poseen determinadas expectativas de reconocimiento que desarrollan en el trayecto de socialización de su vida; en ese sentido, su teoría se aparta de concepciones tradicionales de 
crea la idea de un "sujeto" omnicomprensivo denominado "el otro", que es el sujeto no moderno de la modernidad, un sujeto creado, también, desde la idea del opuesto universalizante, a quien se le crean unas identidades fijas que, en todo caso, de un lado, nunca son recíprocas al sujeto mítico de la modernidad y, de otro lado, eliminan la potencialidad de la performatividad de estas identidades diferenciadas.

Esta manifestación de una forma de operación de reconocimiento de las subjetividades particulares en Colombia se inserta como la excepción ${ }^{65}$, mediante la categoría jurídica de los sujetos y grupos de especial protección, utilizada como la herramienta jurídica para tratar con el otro, esto es, con el sujeto periférico y, a partir de allí, se adopta un modelo de reconocimiento bipolar, es decir, un reconocimiento recíproco entre los individuos que encajan en el sujeto liberal de la modernidad para quien se crea un derecho general y de normalidad, y un reconocimiento diferenciado para el resto, esto es, el reconocimiento de los sujetos especiales en situación de discriminación, marginalidad, debilidad ${ }^{66}$ o desventaja, para quienes se crea un derecho excepcional y de anormalidad; y existe otro resto de sujetos, que no encajan en esa bipolaridad del reconocimiento, es decir, son los no reconocidos y que, por tanto, son aquellos sujetos invisibilizados que no son parte de ninguna parte.

De esta manera, los sujetos y grupos “especiales" se enfrentan a un proceso inevitable y continuo de lucha por sus identidades y la superación de las injusticias de las estructuras sociales de estatus y clase, hacia la búsqueda del reconocimiento de las subjetividades particulares, como lo sostiene Nancy Fraser, cuyo fundamento para

reconocimiento universalizantes y las ubica en el sujeto particular, sin anexarle subjetividades fijas.

65 Jorge GonzÁlez-JÁcome, Exceptionalism as a Colonial Tool in Modern International Law [El excepcionalismo como una herramienta colonial en el derecho internacional moderno], 10 International Law, Revista Colombiana de Derecho Internacional, 15-42 (2007). Disponible en: http:// revistas.javeriana.edu.co/index.php/internationallaw/article/view/13954/11239. González, en este sentido, destaca la excepción como una herramienta de poder y explica cómo el excepcionalismo, en escenarios más amplios, ha servido como un instrumento colonial del derecho internacional moderno, por medio del cual se mantiene el colonialismo local. Valga decir, en el orden local, al replicar esa manera de tratar con el otro, por medio de la especial protección como excepción se le da continuidad a ese proyecto colonial.

66 Con esta denominación se identifica al sujeto excepcional dentro del artículo 13 de la Constitución Política de Colombia. Este calificativo no tiene qué ver con su falta de recurrencia, sino con su exclusión y subordinación frente al sujeto ideal de la modernidad del derecho colombiano. 
el reconocimiento se basa como bien lo afirma Axel Honneth no en posiciones de intereses, sino en sentimientos morales de injusticia ${ }^{67}$.

Así pues, todo lo anterior permite argumentar que el reconocimiento, como origen y fuente de los sujetos y grupos de la especial protección en Colombia, conduce a sostener que el significado de la especial protección gira, en primer lugar, hacia el sentido negativo del término como modo de exclusión y subordinación pero, también, en segundo lugar, hacia el sentido positivo como fundamento y potencialidad de inclusión de los sujetos y grupos excepcionales del derecho colombiano.

\section{LAS CARAS OPUESTAS DEL RECONOCIMIENTO EN LA ESPECIAL PROTECCIÓN}

Con fundamento en lo expuesto, en una teoría de la especial protección, la noción del reconocimiento plantea la existencia de diferentes caras o modelos de reconocimiento que pueden variar con cada sociedad; así pues, pueden deducirse una pluralidad de modelos de reconocimiento: 1) recíprocos, 2) unilaterales, 3) horizontales, 4) verticales, 5) tácitos, 6) explícitos, 7) erróneos, 8) correccionales, 9) amplios, 10) restringidos, 11) completos, 12) incompletos, 13) directos, 14) indirectos, 15) unidimensionales y 16) bidimensionales.

En este orden, puede anotarse que los reconocimientos recíprocos parecen propios de sociedades con democracias de alta intensidad y no con democracias de baja intensidad ${ }^{68}$, en las que se presume que media un acuerdo entre individuos con iguales derechos y se dan en doble vía: del sujeto para con la familia, la sociedad y el Estado y, de todos estos, para con el sujeto; mientras que en los reconocimientos unilaterales, no hay un acuerdo; estos vienen determinados por una sola voluntad que no siempre coincide con el interés de la mayoría o con los sujetos reconocidos; son propios de sociedades con regímenes totalitarios o con democracias de baja intensidad.

67 Axel Honneth, La lucha por el reconocimiento. Por una gramática moral de los conflictos sociales (Crítica, Grijalbo Mondadori, Barcelona, 1992).

68 Barry Gills, Joel Rocamora \& Richard Wilson, Low Intensity Democracy: Political Power and the New World Order (Westview, Boulder, 1993). 
Así pues, entre los grupos de especial protección, las mujeres, desde una perspectiva del sexo - no del género- encuentran mayores grados de reconocimiento recíproco dentro del orden social que el resto de los grupos especiales; en el caso contrario - en los reconocimientos unilaterales-, un ejemplo clave lo constituyen los habitantes de la calle, quienes carecen de ese reconocimiento recíproco, en muchos casos, pues su reconocimiento no siempre coincide con la identificación de los sujetos reconocidos; esto es, muchas personas que viven en la calle son reconocidas por el Estado como habitantes de la calle mientras ellos se reconocen a sí mismos como desplazados y no bajo esa identidad preestablecida por el aparato institucional.

Los reconocimientos horizontales, de otro lado, surgen cuando las partes se encuentran en el mismo nivel, en pie de igualdad y pueden llegar a acuerdos sobre su identidad particular y colectiva y sobre sus derechos. No ocurre igual en los reconocimientos verticales, por cuanto, en estos, siempre median posiciones desiguales entre las partes que hacen que unos sujetos cedan o se vean obligados a asumir los contenidos de reconocimiento asignados por los otros que están ubicados en una posición superior.

En este orden, en el primer caso, teniendo en cuenta la condición necesaria de la igualdad en la realidad solo aplican a unos pocos individuos con exclusión de los sujetos de especial protección, en particular a los "hombres" que encajan en el sujeto liberal de la modernidad. En el segundo caso, siguiendo con el ejemplo de los habitantes de la calle, cuyo reconocimiento depende de la decisión última de un funcionario estatal independientemente de que estas personas encajen en el prototipo jurídico social, es decir, que vivan en la calle, no tengan los recursos para subsistir y se reconozcan como tales, estos asumen una posición subordinada respecto de ese funcionario que representa el Estado y unilateralmente tiene el poder de definir su situación identitaria, incluso, con independencia de su propia identificación.

Los reconocimientos tácitos, por su parte, operan generalmente como reglas implícitas naturalizadas en el interior de la colectividad, en las que se presume un acuerdo, conforme con el cual solo son sujetos de reconocimiento aquellos que se adecúan al prototipo o al modelo de sujeto tradicional dominante de una sociedad de- 
terminada. En cambio, los reconocimientos explícitos son aquellos que requieren algún medio físico, verbal o virtual para afirmar, específicamente, quiénes son sujetos de reconocimiento.

En este punto, se puede traer como ejemplo el caso de las mujeres y los hombres, cuyo reconocimiento dentro del ordenamiento jurídico se sobreentiende como algo naturalizado y presupuesto a partir del sexo y no del género conforme con la situación que se refleja en el campo jurídico y social. En el caso contrario, los reconocimientos lo constituyen aquellos a quienes la Constitución reconoció expresamente en su articulado como sujetos de especial protección como ocurre con los niños, los adolescentes, los ancianos y los discapacitados, incluso, con las mismas mujeres.

El reconocimiento erróneo, a su vez, aparece como la forma de negación injustificada de ciertos sujetos de la sociedad, en su totalidad o en su particularidad, lo que supone el privilegio de unos sujetos visibilizados y con derechos plenos, en perjuicio de otros sujetos invisibilizados. En contraposición, emerge el reconocimiento correccional o remedial, encargado de la identificación de aquellas equivocaciones cometidas en razón al desconocimiento de ciertos sujetos de la sociedad y que se convierte en el fundamento de la corrección de estas injusticias, tradicionalmente cometidas sobre estos sujetos.

En esta doble vía aparecen, entre otros, los menores, los hijos extramatrimoniales, las mujeres, los habitantes de calle, las personas LGBTIQ, los indígenas, los afrodescendientes, etc. Todos ellos cuentan con un proceso histórico de discriminación y un tratamiento especial, que no implica que esas circunstancias ya hayan sido superadas o corregidas de forma plena y adecuada.

En cuanto al reconocimiento ampliado, puede denotar que hay un mayor reconocimiento de unos sujetos frente a otros, pero también que, en una sucesión temporal, ha habido una modificación en el sujeto hacia un ensanchamiento progresivo de su reconocimiento; de otro lado, están los reconocimientos restringidos, aquellos que están limitados a ciertos sujetos privilegiados de la sociedad.

En este escenario, podría hablarse, por ejemplo, de una ampliación del reconocimiento de los habitantes de la calle en materia de atención básica en salud pero restringida en cuanto a derechos de vivienda o de empleo, cuyos privilegios corresponden a otros sectores de la sociedad. 
Así también, pueden hallarse reconocimientos completos, como en aquellas sociedades en las que todos sus miembros son sujetos plenamente reconocidos, dotados de los mismos derechos, con altos estándares de igualdad material, sin excepción alguna; o cuando se ha alcanzado el ideal del reconocimiento esperado por los actores sociales; en contrapartida, aparecen los reconocimientos incompletos, que son aquellos en los cuales un sujeto ha sido reconocido pero no en los mismos términos de plenitud que los demás miembros de la sociedad y, en el fondo, su reconocimiento no es pleno sino limitado, por lo que queda pendiente a futuro completar la parte faltante de su reconocimiento.

En este orden, en el caso colombiano en materia de especial protección es improbable hallar un ejemplo de reconocimiento completo ni siquiera en el caso de mujeres o indígenas que han avanzado en la lucha por sus derechos. En cambio, es más fácil encontrar casos como el de los habitantes de calle, "reconocidos" pero de forma incompleta, en el sentido de que este no garantiza un derecho de habitación en calle o condiciones reales de vida digna como se esperaría por parte de los reconocidos, sino todo lo contrario, les asegura la reproducción de sus circunstancias de menosprecio y opresión; así pues, este ejemplo se hace extensivo a muchos otros sujetos de especial protección que son reconocidos de manera insuficiente e injusta.

Al mismo tiempo, puede haber reconocimientos directos, como aquellos que dependen de la voluntad y la potestad directa de la decisión de cada individuo para reconocer a sus demás coasociados, a la familia y al Estado y viceversa; pero también, puede haber reconocimientos indirectos, aquellos, por medio de los cuales, se da la figura de la representación, en la cual el reconocimiento o el desconocimiento de un sujeto o de un grupo social determinado viene de la intermediación de un tercero, en quien, formalmente, se ha delegado la voluntad para decidir en su nombre.

En este marco, hay un ejemplo en el reconocimiento directo e indirecto en el caso de las mujeres o comunidades negras e indígenas por medio de su cuota de participación directa y representativa en la legislación de sus derechos mientras que en el caso de otros sujetos especiales como los menores de edad, los desplazados y los 
mismos habitantes de la calle, entre otros, solo tienen garantizada una representación formal de sus derechos.

Por último, sin pretender, de ningún modo, cerrar esta clasificación opuesta de los modelos de reconocimiento, aparecen los dos modelos teóricos más destacados en el estudio de la materia, esto es, el modelo unidimensional de la teoría de reconocimiento de Axel Honneth y el modelo bidimensional de la teoría de redistribución y reconocimiento de Nancy Fraser, citados en el acápite anterior.

En el reconocimiento unidimensional, Axel Honneth sostiene que este se origina en una lucha moral en los conflictos sociales no motivados por intereses económicos, individualistas o de autoconservación, sino más bien por la necesidad de tener efectos en la comunidad social; de ahí que la idea de reconocimiento deba ser mirada unidimensionalmente en la motivación moral de los sujetos, fundada en su anhelo o necesidad de estar realmente incluidos en la sociedad, de ser reconocidos dentro de la sociedad ${ }^{69}$.

Mientras tanto, Nancy Fraser confronta esta visión unidimensional del reconocimiento y advierte sobre la necesidad de hablar desde una perspectiva bidimensional del reconocimiento, según la cual este no puede ser visto como una cuestión meramente de autorrealización personal sino desde las relaciones sociales. $\mathrm{Su}$ enfoque lleva a contemplar las reivindicaciones de reconocimiento de la diferencia de forma pragmática y contextual, como respuestas reparadoras de injusticias específicas y preexistentes; para ello, propone una concepción bidimensional que considera la redistribución y el reconocimiento como perspectivas y dimensiones diferentes de la justicia sin reducir una dimensión en la otra ${ }^{70}$.

En este escenario, como ejemplo aplicable a otros sujetos, se puede citar el reiterado caso de los habitantes de la calle, cuyo reconocimiento constituye más un instrumento para su dominación y violencia que para su garantía de derechos. En estos términos, en la medida en que solo constituye una reivindicación de reconocimiento y no de redistribución de recursos económicos, se queda en la perspectiva unidimensional ajena a los intereses de los sujetos

69 Axel Honneth, La lucha por el reconocimiento. Por una gramática moral de los conflictos sociales (Crítica, Grijalbo Mondadori, Barcelona, 1992).

70 Nancy Fraser \& Axel Honneth, ¿Redistribución o reconocimiento?: un debate político-filosófico (Ediciones Morata, Madrid, 2003). 
reconocidos. En cambio, en el caso de las mujeres y de los desplazados pueden hallarse ejemplos bidimensionales que implican al mismo tiempo reconocimiento y redistribución; sin embargo, estas fórmulas de reivindicación no están libres de cuestionamientos y se hace necesario examinarlas en cada caso.

Ahora bien, estos dos últimos modelos de reconocimiento, importantes para el estudio de la especial protección, se dedican a descifrar la razón o la naturaleza del reconocimiento y terminan por plantear dos teorías generales que omiten hablar de las caras opuestas del reconocimiento y de su performatividad de acuerdo con los diferentes contextos sociales, por lo que caen en el error de las teorías universalizantes con pretensiones de verdad y certeza.

Por supuesto, cada uno de estos modelos incide directamente en la forma y el contenido que determinan el objeto jurídico de la especial protección, por lo que se convierte no solo en el antecedente necesario, sino también en su fundamento.

En Colombia, entonces, ese modelo de reconocimiento en los sujetos y grupos de especial protección — visto desde el derecho estatal, de forma dominante - se presenta unilateral, vertical, explícito, erróneo, restringido, incompleto, indirecto y sin fundamento teórico reconocible en una perspectiva unidimensional o bidimensional de la justicia, encerrado en el discurso del derecho moderno de la colonización en un período posmoderno y poscolonial actual.

El reconocimiento actual de estos sujetos y colectivos reproduce un discurso de exclusión de estas y otras subjetividades invisibilizadas, mediante el sistema jurídico-estatal, en la medida en que fija y reconoce en estos sujetos una identidad desde el Estado hacia los sujetos, subordina e instrumentaliza esas identidades a sus propósitos, lo hace de forma expresa mediante el derecho positivo; mediante la inclusión del sujeto opuesto niega la construcción propia de las identidades reconocidas como especiales y aquellas otras que ni siquiera alcanzan esta categoría, con lo cual mantiene la desigualdad entre sus ciudadanos; por tanto, no existe por medio de la categoría jurídica de la especial protección una perspectiva unidimensional de la justicia que, mediante un reconocimiento recíproco garantice materialmente la dignidad y la identidad plural de los sujetos en su totalidad, ni tampoco una perspectiva bidimensional, que garantice la eliminación de las estructuras de estatus y de clase que oprimen las subjetividades despreciadas. 


\section{CONCLUSIONES}

Analizada la relación entre la especial protección y el reconocimiento, puede concluirse que en el caso colombiano la concepción de la categoría jurídica de los sujetos y grupos de especial protección solo ha sido considerada discursivamente bajo la concepción positiva del término, a partir del "reconocimiento recíproco" de sus miembros, como si se tratara de un reconocimiento razonable y justo correlativo entre el Estado y los sujetos, y entre ellos mismos, incluso, asumiendo indiscutidamente que este modelo de reconocimiento ha sido aceptado pacíficamente, lo cual ha permitido dentro del derecho estatal establecer clasificaciones entre los sujetos coasociados, entre sujetos de normal protección y sujetos de "especial protección", lo que oscurece el sentido negativo de esta institución jurídica.

Esto es, la figura de la especial protección en Colombia se muestra como un instrumento positivo, por medio del cual se reconocen los sujetos y grupos "en posición de desventaja" con el resto de la sociedad para realizar su proyecto de vida en condiciones dignas y justas y, a partir de ese reconocimiento, reivindicar una especial protección de acuerdo con sus necesidades. Pero aquella institución no ha sido puesta en tela de juicio como sistema para mantener privilegios injustificados a favor de ciertos sujetos y grupos o para identificar a aquellos que se encuentran en situación de desventaja para hacer más gravosa sus condiciones de existencia o para invisibilizar aún más a otros sujetos.

En este sentido, no puede omitirse ingenuamente que el objeto jurídico de la especial protección dentro del derecho colombiano tiene una cara oculta que esconde el sentido negativo de esta categoría jurídica; esto es, está construida con base en la exclusión de los sujetos y grupos llamados especiales que no encajan en el sujeto liberal de la modernidad, a los cuales por medio de esta figura se les inventa un derecho excepcional y paralelo al derecho ordinario, con lo cual se reproduce el discurso del derecho injusto de la modernidad, cuya fórmula de la igualdad material basada en las diferencias de los sujetos - además de quedarse en una nueva forma de igualdad formal - ahonda la brecha de la desigualdad con base en una serie de reconocimientos precarios de los sujetos. 
En conclusión, en un sentido crítico, la categoría jurídica de la especial protección en Colombia no escapa a la contradicción de ese sentido positivo y negativo del término como tampoco al uso discursivo de un reconocimiento que aparenta ser de una cara positiva: recíproco, horizontal, explícito, correccional, ampliado, completo, directo, unidimensional y bidimensional; cuando en la realidad, conserva también una cara negativa: unilateral, vertical, tácito, erróneo, restringido, incompleto e indirecto.

El interrogante que deja este estudio es cómo superar o enfrentar ese sentido negativo de la categoría jurídica de la especial protección, frente a lo cual parece necesario apelar, en principio, a lo que Boaventura de Sousa-Santos ha propuesto: La reinvención del Estado y el Estado Plural, mediante el cual se sugiere implementar un constitucionalismo experimental, que niegue el discurso centralista occidental y promueva un real pluralismo jurídico ${ }^{71}$.

El Estado colombiano tiene que reinventar la forma de reconocimiento del derecho mismo para reconocer a todos los individuos y a los colectivos en su totalidad a partir del respeto de sus diferencias y entrar en un diálogo real de reconocimiento recíproco con los demás órdenes normativos de la sociedad, sin caer en el discurso colonial de un derecho esencialista y vertical en desprecio de los demás órdenes normativos y de la performatividad de los sujetos y las colectividades.

El derecho colombiano, igualmente, debe corregir o eliminar el modelo de derecho excepcional introducido con la categoría jurídica de la especial protección y el reconocimiento de los llamados sujetos y grupos de especial protección, que no pueden seguir siendo tratados de forma excepcional, mediante un remedo de derecho especial que los excluye, oprime y contribuye con el mantenimiento de las estructuras de estatus y de clase en el contexto colombiano.

El Estado colombiano, por consiguiente, está obligado a garantizar un modelo de reconocimiento diferente (recíprocos, horizontales, explícitos, correccionales, amplios, completos, directos, unidimensionales y bidimensionales) que garantice la existencia de ciudadanías plenas y no precarias para todos; pero para ello

71 Boaventura de Sousa-Santos, La reinvención del Estado y el Estado Plural, 7 Observatorio Social de América Latina, OSAL 22, 25-46 (2007). Disponible en: http://bibliotecavirtual.clacso.org.ar/ar/ libros/osal/osal22/D22SousaSantos.pdf 
son necesarios cambios estructurales en el reconocimiento de los sujetos, en la concepción y operatividad del derecho, y en las reivindicaciones de justicia de reconocimiento y en las reivindicaciones de redistribución que continúan pendientes.

En este sentido, un derecho de especial protección que sea repensado y refundado a partir de la idea de un reconocimiento recíproco entre el Estado y los sujetos y entre ellos mismos, el empoderamiento y la agencia política de los sujetos y las colectividades, la garantía de espacios para los movimientos y las luchas sociales, la articulación de órdenes plurales para enfrentar y eliminar las estructuras coloniales de estatus y de clase, por medio de una reestructuración económica y el incremento de la valoración social del sujeto en su totalidad y su diferencia pueden ser las bases iniciales de un nuevo enfoque del derecho en Colombia y de una nueva realidad. 


\section{BIBLIOGRAFÍA}

\section{Libros}

Butler, Judith, El género en disputa. El feminismo y la subversión de la identidad (Ediciones Paidós, Barcelona, 1990).

Castro-Gómez, Santiago, La poscolonialidad explicada a los niños (Editorial Universidad del Cauca, Instituto Pensar, Pontificia Universidad Javeriana, Bogotá, 2005).

Dussel, Enrique, 1492: El encubrimiento del otro. El origen del mito de la modernidad (Antropos, Bogotá, 1992).

FitzPatrick, Peter, La mitología del derecho moderno (Siglo XXI, México, 1998).

Fraser, NANCY \& HonNeth, Axel, ¿Redistribución o reconocimiento?: un debate políticofilosófico (Ediciones Morata, Madrid, 2003).

Gills, Barry; Rocamora, Joel \& Wilson, Richard, Low Intensity Democracy: Political Power and the New World Order (Westview, Boulder, 1993).

Hardt, Michael \& Negri, Antonio, Imperio (Ediciones Desde Abajo, Bogotá, 2001).

Hart, Herbert, El concepto del derecho (Abeledo Perrot, Buenos Aires, 1941).

Hegel, Georg Wilhelm Friedrich, Fenomenología del espíritu [Phänomenologie des Geistes] (Wenceslao Roces \& Ricardo Guerra, trads., Fondo de Cultura Económica, FCE, México, 1971).

Honneth, Axel, La lucha por el reconocimiento. Por una gramática moral de los conflictos sociales (Crítica, Grijalbo Mondadori, Barcelona, 1992).

Kelsen, Hans, La teoría pura del derecho (Editorial Trotta, Madrid, 1934).

López-Medina, Diego, La letra y el espíritu de la ley: reflexiones pragmáticas sobre el lenguaje del derecho y sus métodos de interpretación (Editorial Temis, Bogotá, 2008).

Mead, George Herbert, Espíritu, persona y sociedad [Mind, Self and Society] (Floreal Macía, trad., Paidós, Buenos Aires, 1953).

Monateri, Pier Giuseppe \& Samuel, Geoffrey, La invención del derecho privado (Siglo del Hombre Editores, Bogotá, 2006).

Twining, William, Derecho y globalización (Siglo del Hombre Editores, Bogotá, 2003).

Wallerstein, Immanuel, El análisis de sistemas-mundo (Carlos Daniel Schroeder, trad., Siglo XXI, México, 2005).

\section{Contribuciones en obras colectivas}

Gargarella, Roberto, Argumentos y contraargumentos en la discusión sobre los derechos de los grupos desaventajados, en Derecho y grupos desaventajados, 23-30 (RoBERTO Gargarella, comp., Gedisa, Barcelona, 1999).

Gargarella, Roberto, Los déficits del sistema político representativo, en Derecho y grupos desaventajados, 13-15 (Roberto Gargarella, comp., Gedisa, Barcelona, 1999). 
Gargarella, Roberto, Sobre el tipo de criterios y reformas institucionales que se sugieren en el presente volumen, en Derecho y grupos desaventajados, 16-22 (ROBERTO Gargarella, comp., Gedisa, Barcelona, 1999).

Lindahl, Hans, Constituent Power and Reflexive Identity: Towards an Ontology of Collective Selfhood, en The Paradox of Constitutionalism, 9-24 (Martin Loughuin \& Neil Walker, eds., Oxford University Press, Oxford, 2007).

Mignolo, Walter, Capitalismo y geopolítica del conocimiento. El eurocentrismo y la filosofía de la liberación en el debate intelectual contemporáneo (WALter MignOLO, comp., Ediciones del Signo, Duke University, Buenos Aires, 2001).

\section{Revistas}

GonzÁlez-JÁCOME, JoRge, Exceptionalism as a Colonial Tool in Modern International Law [El excepcionalismo como una herramienta colonial en el derecho internacional moderno], 10 International Law, Revista Colombiana de Derecho Internacional, 15-42 (2007). Disponible en: http://revistas.javeriana.edu.co/index.php/ internationallaw/article/view/13954/11239

Peláez-Grisales, Holmedo, Una mirada al problema del derecho de los sujetos y grupos desaventajados de especial protección en Colombia y la apuesta por una necesaria fundamentación teórica desde las teorías contemporáneas de la justicia, 17 Estudios Socio-Jurídicos, 1, 125-168 (2015). Disponible en: https://revistas.urosario.edu. co/index.php/sociojuridicos/article/view/3289/2631

Rajagopal, Balakrishnan, Invoking the Rule of Law in Post-conflict Rebuilding: A Critical Examination, 49 William \& Mary Law Review, 4, 1347-1376 (2008). Disponible en: $\mathrm{http}: / /$ scholarship.law.wm.edu/cgi/viewcontent.cgi?article $=1145 \&$ context $=$ wmlr

Sousa-Santos, Boaventura De, La reinvención del Estado y el Estado Plural, 7 Observatorio Social de América Latina, OSAL 22, 25-46 (2007). Disponible en: http://bibliotecavirtual.clacso.org.ar/ar/libros/osal/osa122/D22SousaSantos.pdf

Tamanaha, Brian Z., The Dark of the Relationship between the Rule of Law and Liberalism, 3 NYU Journal of Law \& Liberty, 516-547 (2008). Disponible en: http://www.law.nyu.edu/sites/default/files/ECM_PRO_060975.pdf

\section{Normativa}

Constitución Política de la República de Colombia de 1991. Bogotá: Editorial Legis.

Colombia, Constitución Política de 1886, 5 de agosto de 1886. Disponible en: http:// www.alcaldiabogota.gov.co/sisjur/normas/Norma1.jsp?i=7153

Colombia, Constitución Política de 1991, versión corregida 116 Gaceta Constitucional, 20 de julio de 1991. Disponible en: http://www.secretariasenado.gov.co/senado/ basedoc/constitucion_politica_1991.html

Colombia, Ley 1641 de 2013, por la cual se establecen los lineamientos para la formulación de la política pública social para habitantes de la calle y se dictan otras disposiciones, 48.849 Diario Oficial, 12 de julio de 2013. Disponible en: 
http://www.secretariasenado.gov.co/senado/basedoc/ley_1641_2013.html

\section{Jurisprudencia colombiana}

Corte Constitucional, Sentencia C-371-00, 29 de marzo de 2000, magistrado ponente Carlos Gaviria-Díaz. Disponible en: http://www.corteconstitucional.gov.co/ RELATORIA/2000/C-371-00.htm

Corte Constitucional, Sentencia C-1036-03, 5 de noviembre de 2003, magistrada ponente Clara Inés Vargas-Hernández. Disponible en: http://www.corteconstitucional. gov.co/relatoria/2003/c-1036-03.htm

Corte Constitucional, Sentencia C-385-14, 25 de junio de 2014, magistrado ponente Gabriel Eduardo Mendoza-Martelo. Disponible en: http://www. corteconstitucional.gov.co/relatoria/2014/c-385-14.htm

Corte Constitucional, Sentencia C-767-14, 16 de octubre de 2014, magistrado ponente Jorge Ignacio Pretelt-Chaljub. Disponible en: http://www.corteconstitucional. gov.co/relatoria/2014/c-767-14.htm

Corte Constitucional, Sentencia T-426-92, 24 de junio de 1992, magistrado ponente Eduardo Cifuentes-Muñoz. Disponible en: http://www.corteconstitucional.gov. co/relatoria/1992/t-426-92.htm

Corte Constitucional, Sentencia T-347-96, 8 de agosto de 1996, magistrado ponente Julio César Ortiz-Gutiérrez. Disponible en: http://www.corteconstitucional. gov.co/relatoria/1996/t-347-96.htm

Corte Constitucional, Sentencia T-500-02, 27 de junio de 2002, magistrado ponente Eduardo Montealegre-Lynett. Disponible en: http://www.corteconstitucional. gov.co/relatoria/2002/t-500-02.htm

Corte Constitucional, Sentencia T-1093-12, 18 de diciembre de 2012, magistrado ponente Luis Ernesto Vargas-Silva. Disponible en: http://www.corteconstitucional.gov. co/relatoria/2012/t-1093-12.htm

Corte Constitucional, Sentencia T-043-14, 31 de enero de 2014, magistrado ponente Luis Ernesto Vargas-Silva. Disponible en: http://www.corteconstitucional.gov. co/relatoria/2014/t-043-14.htm

Corte Constitucional, Sentencia T-025-15, 23 de enero de 2015, magistrado ponente Gabriel Eduardo Mendoza-Martelo. Disponible en: http://www. corteconstitucional.gov.co/relatoria/2015/t-025-15.htm

Corte Constitucional, Sentencia T-032-15, 26 de enero de 2015, magistrado ponente Jorge Ignacio Pretelt-Chaljub. Disponible en: http://www.corteconstitucional. gov.co/relatoria/2015/t-032-15.htm

Corte Constitucional, Sentencia T-092-15, 5 de marzo de 2015, magistrada ponente Gloria Stella Ortiz-Delgado. Disponible en: http://www.corteconstitucional. gov.co/relatoria/2015/t-092-15.htm

Corte Constitucional, Sentencia T-275-15, 12 de mayo de 2015, magistrada ponente María Victoria Calle-Correa. Disponible en: http://www.corteconstitucional. gov.co/relatoria/2015/t-275-15.htm 